Sérgio Ricardo da Costa

\title{
Estudo comparativo da osteotomia femoral varizante em cunha de abertura lateral orientada pelo método convencional $X$ navegação
}

Dissertação apresentada à Faculdade de Medicina da Universidade de São Paulo para obtenção do título de Mestre em Ciências.

Programa de Ortopedia e Traumatologia

Orientador: Dr. Roberto Freire da Mota e Albuquerque 
Sérgio Ricardo da Costa

\section{Estudo comparativo da osteotomia femoral varizante em cunha de abertura lateral orientada pelo método convencional $X$ navegação}

Dissertação apresentada à Faculdade de Medicina da Universidade de São Paulo para obtenção do título de Mestre em Ciências.

Programa de Ortopedia e Traumatologia

Orientador: Dr. Roberto Freire da Mota e Albuquerque 
Dados Internacionais de Catalogação na Publicação (CIP)

Preparada pela Biblioteca da

Faculdade de Medicina da Universidade de São Paulo

\section{Creprodução autorizada pelo autor}

Costa, Sérgio Ricardo da

Estudo comparativo da osteotomia femoral varizante em cunha de abertura lateral orientada pelo método convencional x navegação / Sérgio Ricardo da Costa. -- São Paulo, 2013.

Dissertação(mestrado)--Faculdade de Medicina da Universidade de São Paulo.

Programa de Ortopedia e Traumatologia.

Orientador: Roberto Freire da Mota e Albuquerque.

Descritores: 1.Osteotomia 2.Joelho 3.Fêmur 4.Osteoartrose 5.Cirurgia assistida por computador

USP/FM/DBD-171/13 
À minha esposa Andréa Pereira, amiga, companheira e confidente de todos estes anos. Aos meus filhos Isadora e Rafael por fazerem de nós uma família. 


\section{AGRADECIMENTOS}

Especial ao Dr. Roberto Freire da Mota e Albuquerque, meu orientador, por ter me escolhido como aluno deste mestrado, pela confiança, apoio e crença em todas as fases deste estudo.

A todos os pacientes participaram deste estudo, e são a razão de qualquer aprimoramento.

Aos Professores Doutores Olavo Pires de Camargo, Tarcísio E. P. de Barros Filho e Gilberto Luís Camanho pela oportunidade de realizar este trabalho no Instituto de Ortopedia e Traumatologia do Hospital das Clínicas da Faculdade de Medicina da Universidade de São Paulo.

Aos doutores André Pedrinelli, Marcelo Rosa de Rezende e Dra. Márcia Uchoa Rezende membros da banca de qualificação pela oportunidade, paciência e orientação.

À Faculdade de Medicina da Universidade de São Paulo, pela oportunidade de realização do curso de mestrado.

Aos meus pais, Lourival e Josefa (in memoriam), pelos ensinamentos diários. 
As secretárias Leide de Souza Salomão, Rosana Moreno da Costa e

Tânia Borges, pelas pacientes orientações dadas durante este mestrado.

As bibliotecárias Julietti de Andrade e Camila Gomes da Rocha pelo auxílio nas pesquisas bibliográficas e a bibliotecária Andressa da Costa Santos Souza pela solicitude dos ajustes gráficos e revisão bibliográfica desta dissertação. 


\section{NORMALIZAÇÃO ADOTADA}

Esta dissertação ou tese está de acordo com as seguintes normas, em vigor no momento desta publicação: Referências: adaptado de International Committee of Medical Journals Editors (Vancouver).

Universidade de São Paulo. Faculdade de Medicina. Divisão de Biblioteca e Documentação. Guia de apresentação de dissertações, teses e monografias. Elaborado por Anneliese Carneiro da Cunha, Maria Julia de A. L. Freddi, Maria F. Crestana, Marinalva de Souza Aragão, Suely Campos Cardoso, Valéria Vilhena. 3a ed. São Paulo: Divisão de Biblioteca e Documentação; 2011.

Abreviaturas dos títulos dos periódicos de acordo com List of Journals Indexed in Index Medicus. 


\section{SUMÁRIO}

Lista de tabelas

Lista de figuras

Lista de gráficos

Resumo

Summary

1 INTRODUÇÃO.

2 OBJETIVO

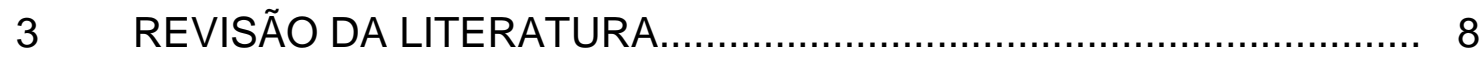

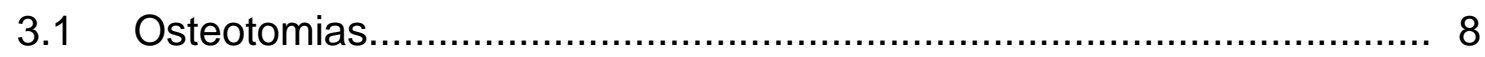

3.2 Cirurgia ortopédica e a navegação........................................... 18

3.3 Osteotomia femoral e navegação............................................ 22

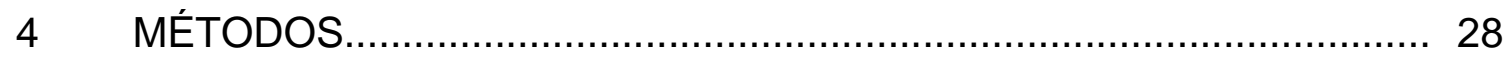

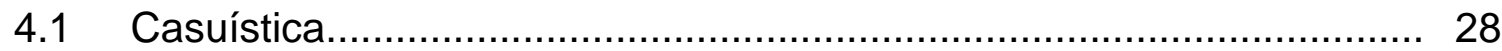

4.2 Critérios de inclusão................................................................. 29

4.3 Critérios de exclusão................................................................ 30

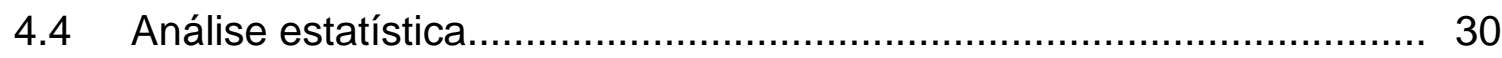

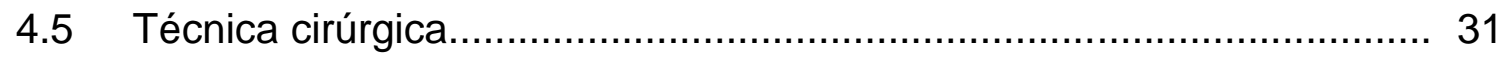

4.5.1 Navegação.......................................................................... 32

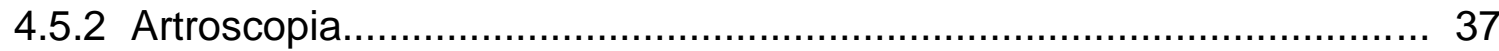

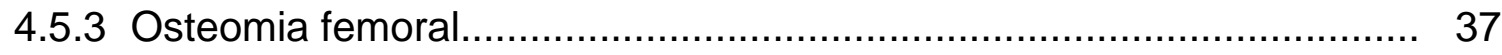

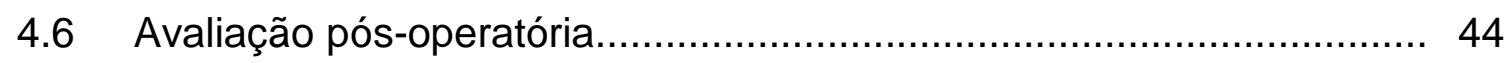

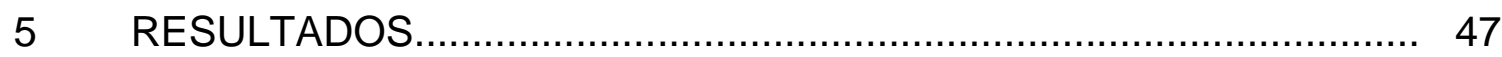




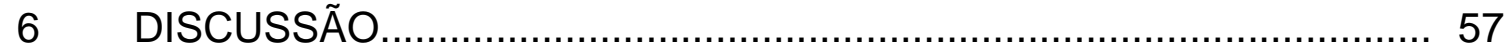

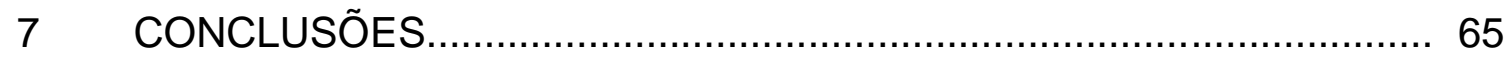

8 ANEXOS

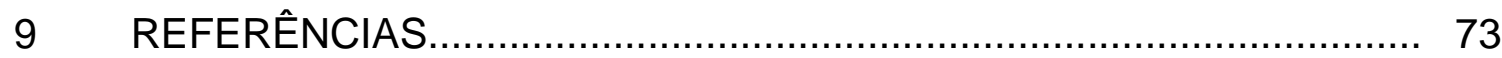




\section{LISTA DE TABELAS}

Tabela 1 Distribuição entre os grupos 48

Tabela 2 Comparação do alinhamento pré-operatório e pós-operatório entre os grupos. 50

Tabela 3 Média e desvio padrão do alinhamento mecânico pós-operatório: técnica convencional e navegação 50

Tabela 4 Valores fora da margem de erro por grupo. 53

Tabela 5 Comparação do escore KSS entre os grupos. ${ }^{(*)}$ Knee society score system 


\section{LISTA DE FIGURAS}

Figura 1 Fotografia do "Tracker"

Figura 2 Fotografia do "Pointer". 33

Figura 3 Membro inferior com "Trackers" posicionados

Figura 4 Alimentação do navegador através da Artroscopia.....

Figura 5 Imagem do navegador "solicitando" os pontos anatômicos de referencia (epicôndilo medial e maléolo medial).

Figura 6 Fotografia da via de acesso lateral (músculo vasto lateral devulcionado superiormente). Identifica-se a cortical lateral do fêmur

Figura 7 Fotografia do fêmur distal com 3 fios e osteótomo 39

Figura 8 Imagem de radioscopia onde se identifica 0 fêmur distal e o posicionamento dos três fios de Kirchner

Figura 9 Fotografia do fêmur distal no momento da fixação da placa, ao mesmo tempo, orientação do alinhamento pelo navegador.

Figura 10 Após a fixação da placa verifica-se: o ADM do membro, e o alinhamento pelo navegador

Figura 11 Radiografia dos mmii demonstrando o eixo.

Figura 12 Radiografia em AP e P de joelho, aspecto pré e pós-operatório de osteotomia femoral

Figura 13 Fotografia da sala cirúrgica, durante ato

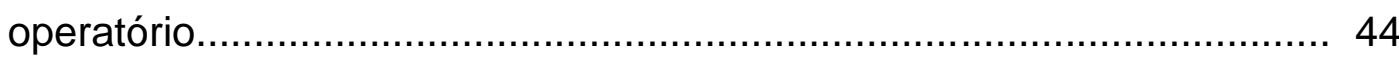

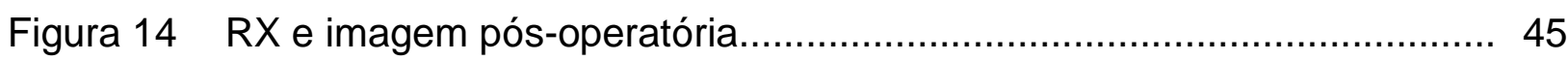




\section{LISTA DE GRÁFICOS}

Gráfico 1 Histograma de Idade por grupos (submetidos à cirurgia com uso de navegação e pela técnica convencional)

Gráfico 2 Painel gráfico de linha de dados do tempo de garrote pelo tempo de cirurgia por tipo de procedimento (tempo em minutos)

Gráfico 3 Box plot do alinhamento pré e pós-operatório por tipo de técnica utilizada

Gráfico 4 Scatter plot com linha de correlação entre alinhamento inicial e final para o grupo com uso de navegação. B. Scatter plot com linha de correlação entre alinhamento inicial e final para o grupo com uso de técnica convencional.

Gráfico 5 Box plot do escore KSS do pré e pós-operatório entre os tipos de técnicas utilizadas. 
RESUMO 


\section{RESUMO}

Costa SR. Estudo comparativo da osteotomia femoral varizante em cunha de abertura lateral orientada pelo método convencional $X$ navegação [dissertação]. São Paulo: Faculdade de Medicina, Universidade de São Paulo; 2013.

INTRODUÇÃO: As osteotomias são formas reconhecidas de tratamento da osteoartrose de joelho em pacientes jovens com desvio do eixo mecânico. A navegação tem sido estudada nos últimos anos como um auxiliar importante nas cirurgias ortopédicas, principalmente artroplastias e oesteotomias. OBJETIVO: Objetivo deste trabalho é comparar, em curto prazo, os resultados radiográficos e clínicos da osteotomia femoral varizante em cunha de adição pelo método convencional e por navegação. MÉTODOS: Avaliamos 25 pacientes no Ambulatório de Especialidades do Hospital Geral de Pedreira, 12 submetidos à osteotomia femoral com navegação e 13 pela técnica convencional. RESULTADOS: Observamos para o grupo da osteotomia com navegação 73, 69 m de tempo de cirurgia com 12, 53 de desvio padrão; $59 \mathrm{~m}$ de tempo de garroteamento. Com relação ao alinhamento mecânico, no pré-operatório a média absoluta foi de 13,84 para cirurgia convencional e 14,4 para a técnica com navegação ( $p=0.7432$; IC95\% 12,8 -15,4), No pós-operatório o alinhamento final mecânico variou de -2 a 3 e, não foi diferente entre as técnicas aplicadas ( $p=0.1316$; IC95\% 0,08-1,24). Porém, obtivemos uma alta correlação $(p=-0,68)$ para o grupo com navegação e uma baixa correlação $(p=-0,07)$ para o grupo 
convencional. CONCLUSÃO: Observamos diferença estatística nos parâmetros: tempo de garroteamento e tempo de cirurgia. Não observamos diferença estatística nos parâmetros: alinhamento mecânico pré e pós; e no escore do HSS.

Descritores: Osteotomia; Joelho, Fêmur; Osteoartrose; Cirurgia assistida por computador. 
SUMMARY 


\section{SUMMARY}

Costa SR. Comparative study of femoral varus osteotomy for lateral opening wedge computer assisted $x$ conventional technique [dissertation]. São Paulo: "Faculdade de Medicina, Universidade de São Paulo"; 2013.

INTRODUCTION: Osteotomies are recognized forms of treatment of knee osteoarthrosis in young patients with mechanical axis deviation. Navigation has been studied in recent years as an important aid in orthopedic surgeries, mainly in arthroplasty and osteotomies. OBJECTIVE: Objective of this study is to compare short-term clinical and radiographic results of femoral varus osteotomy wedge performed by conventional method and by navigation. METHODS: We evaluated 25 patients in Hospital Geral de Pedreira 12 underwent femoral osteotomy with navigation and 13 by conventional technique. RESULTS: As a result, time of surgery was statistically different between techniques $(p=0.0046)$ with a mean (standard deviation) of 73.69 $\mathrm{m}$ (12.53) for the conventional technique and $92.75 \mathrm{~m}$ (16.49) technique with navigation. Regarding to mechanical alignment, preoperative mean was 13.84 for conventional surgery and 14.4 for navigation technique $(p=0.7432$, $95 \% \mathrm{Cl} 12.8-15.4)$ Postoperatively final mechanic alignment ranged from -2 to 3 , and was not different between the techniques applied $(p=0.1316,95 \%$ Cl 0.08 to 1.24$)$. However, we obtained a high correlation $(p=-0.68)$ for the group with navigation and a low correlation $(p=-0.07)$ for the conventional group. CONCLUSION: There were statistical differences in the parameters: 
time of surgery and tourniquet time. No statistical difference in the parameters: mechanical alignment before and after, and the HSS score

Descriptors: Osteotomy; knee; Femur; Osteoarthritis; Surgery, ComputerAssisted. 
1. INTRODUÇÃO 


\section{INTRODUÇÃO}

A osteoartrose primária de joelho é uma doença inflamatória, degenerativa, progressiva e universal, tem uma prevalência de 12\% (em adultos com mais 45 anos) nos EUA (Dillon et al., 2006), 19\% no Reino Unido (Scott et al., 2004). A osteoartrose (AO) produz um impacto socioeconômico importante, uma vez que é responsável pelo afastamento temporário ou definitivo de atividades laborativas, esportivas e, da mesma maneira, do afastamento do convívio social e perda da capacidade de deambular dos pacientes acometidos por ela (Symmons et al., 2002).

Há uma expectativa do aumento da prevalência de osteoartrose do joelho paulatinamente com o aumento da expectativa de vida e da obesidade na população mundial.

Economicamente, a osteoartrose é uma das 5 causas mais frequentes de afastamento do trabalho e o gasto anual devido as artroplastias totais de quadril e de joelho está em torno 7 bilhões de dólares anuais, nos EEUU. Com uma incidência de 240 casos novos por 100.000 habitantes (CDC, 2013), há uma necessidade de novas formas de tratamento.

Analgésicos, anti-inflamatórios, fisioterapia, exercícios físicos, redução do peso corporal, drogas condroprotetoras, viscosuplementação e outras fazem parte do arsenal terapêutico não-cirúrgico da osteoartrose. 
Durante o curso natural da osteoatrose primária de joelho, podem acontecer alterações do alinhamento fêmoro-tibial que modificam a distribuição de cargas nos compartimentos medial e lateral do joelho. Quando este desvio é em varo, há um aumento progressivo da transmissão de cargas para o lado medial. Quando é em valgo, há um aumento das cargas no lado lateral.

Este aumento de carga unilateral sobrecarrega mecanicamente a articulação e gera lesão à cartilagem hialina. Alterações estruturais e a perda das propriedades biomecânicas originais da cartilagem promovem a formação de cistos subcondrais, afilamento da cartilagem, esclerose subcondral e formação de osteófitos (Kettelkamp \& Chao, 1972). Este ciclo gera dor e limitação de mobilidade articular.

A artroscopia, a artroplastia total de joelho e a osteotomia são as formas mais frequentes de tratamento cirúrgico da osteoartrose do joelho.

Quando a osteoartrose cursa com desvio do eixo fêmoro-tibial. As osteotomias podem ser consideradas como uma das formas de tratamento cirúrgico. Pacientes com menos de 55 anos, com boa mobilidade articular e ativos são os mais indicados para as osteotomias (Coventry, 1985).

As osteotomias podem ser realizadas, de maneira geral, na tíbia proximal ou no fêmur distal; podem ser de cunha de adição ou subtração; e 
podem ser fixadas com placas e parafusos ou por fixação externa. De maneira geral, a popularidade das osteotomias entre os ortopedistas diminuíram com melhoria da longevidade e da técnica das próteses de joelho (Wright et al., 1995).

$\mathrm{Na}$ osteoartrose com joelho em valgo, a osteotomia do fêmur distal varizante tem como objetivo corrigir o eixo fêmoro-tibial, para valores normais entre 7 e 10 graus no eixo anatômico, ou 0 grau no eixo mecânico.

O alinhamento final do membro após a osteotomia femoral é ao mesmo tempo: um desafio; e um dos princípios mais importantes para os bons resultados clínicos e radiográficos desta técnica. Alguns estudos são claros em relacionar o alinhamento final do membro com os resultados, assim como, com a longevidade da osteotomia (Finkelstein et al., 1996).

Há mais de duas décadas ortopedistas têm estudado a fundo novos métodos para melhorar as técnicas cirúrgicas ortopédicas e suas limitações, principalmente no que tange ao posicionamento protético e alinhamento dos membros inferiores.

A cirurgia ortopédica assistida por computador - Computer Aided Orthopedic Surgery (CAOS), termo estabelecido em Davos, 2001, já tem sido largamente estudadas e aplicadas nas artroplastias de joelho e quadril, nestes procedimentos advoga-se que o navegador forneça dados precisos 
para o posicionamento inequívoco dos componentes protéticos e consequentemente um alinhamento adequado dos membros. Desta forma, o cirurgião pode, durante 0 ato operatório, confirmar o alinhamento final do membro, aumentando a sobrevida dos implantes e melhorando os bons resultados em longo prazo (Sparmann et al., 2003).

Alguns estudos têm demonstrado vantagens nos procedimentos ortopédicos que utilizam a navegação sobre aqueles que utilizam as técnicas convencionais no que tange ao alinhamento final dos membros inferiores e sua relação direta com resultados clínicos melhores, principalmente nas artroplastias e nas osteotomias tibiais (Saragaglia et al., 2005; Maurer \& Wassmer, 2006).

Há uma escassez de trabalhos sobre as osteotomias femorais que utilizem a navegação como ferramenta cirúrgica.

A motivação do presente estudo foi estudar os possíveis benefícios deste sistema de navegação sobre a técnica de osteotomia femoral distal varizante e sobre seus resultados iniciais, particularmente sobre 0 alinhamento final do membro inferior tendo em vista as evidências de sua importância para a longevidade dos resultados obtidos. 
2. OBJETIVO 
2 OBJETIVO

O objetivo deste estudo é avaliar, em curto prazo, os resultados de pacientes com osteoartrose unicompartimental lateral submetidos à osteotomia femoral distal varizante com o auxílio do navegador nos parâmetros abaixo:

- Tempo de cirurgia;

- Tempo de garrote;

- Alinhamento pré-operatório (mecânico);

- Correção atingida no pós-operatório;

E compará-los, estatisticamente, com pacientes submetidos ao mesmo procedimento com a técnica convencional. 
3. REVISÃO DA

LITERATURA 


\section{REVISÃO DA LITERATURA}

\subsection{Osteotomias}

As osteotomias têm sido largamente utilizadas como tratamento cirúrgico da osteoartrose unicompartimental sintomática em joelhos com desvio do eixo fêmoro-tibial e com bons resultados em curto e médio prazo. Embora as indicações das osteotomias não sejam absolutas: a dor articular, o estreitamento do espaço articular, os desvios do eixo mecânico em varo ou valgo são as mais referidas. Tais características são geralmente encontradas em pacientes mais jovens e ativos nos quais a artroplastia total do joelho seria um procedimento muito agressivo e limitante.

A ideia de correção de deformidades ósseas nos membros inferiores surgiu com Hipócrates (460-370ac.), que desenvolveu um aparato de tração para este fim (Hippocratic Scamnum).

Somente em 1834, John Rhea Barton descreve o primeiro relato de osteotomia femoral supracondiliana ao redor do joelho realizada com sucesso. 
Em 1958, Jackson relata uma serie de seis osteotomias femorais e 8 tibiais em pacientes com osteoartrose e deformidade em valgo, mas somente em 1961, juntamente com Waugh, apresentam evidência radiográfica da correção do eixo e da consolidação óssea em 11 casos, com seguimento de 31 meses (Jackon, 1958; Jackson \& Waugh, 1961).

Em 1972, Kettelkamp \& Chao demonstram que a angulação em varo faz com que a transmissão de cargas ocorra principalmente pelo compartimento medial, angulação entre 0 e 6 graus de valgo, promovendo a distribuição entre os dois compartimentos. $\mathrm{E}$, a angulação com $7^{\circ}$ valgo ou mais, reduz a carga no compartimento medial de modo importante; sobrecarregando o compartimento lateral, gerando afrouxamento das estruturas mediais, o que proporciona um aumento da deformidade em valgo, e assim sucessivamente, em um ciclo vicioso.

De acordo com Coventry (1973) deve-se realizar uma super correção de 5 graus além do valgo fisiológico (de 5 a 8 graus) para se obter bons resultados em longo prazo. E, as osteotomias devem satisfazer seis critérios:

$\checkmark$ Reverter completamente a deformidade;

Ser próxima a sede da deformidade;

$\checkmark$ Envolver osso que consolide rapidamente, geralmente osso esponjoso;

$\checkmark$ Permitir movimentação e apoio precoce; 
$\checkmark$ Permitir a exploração do joelho se necessário;

$\checkmark$ Ser de fácil execução.

Em 1974, Kettelkamp propõe que a osteotomia proximal da tíbia com ressecção cuneiforme em joelhos varos, utilizando a incisão transversa, a ressecção da cortical medial da cabeça da fíbula e fixação com agrafes. Relaciona mal resultados com correções insuficientes ou exageradas e, com problemas intra-articulares.

Harding (1976) publica artigo no qual 132 pacientes (joelhos) com artrose unicompartimental sendo 76 em varo e 56 em valgo. Todos foram submetidos à osteotomia tibial varizante ou valgizante em cunha de subtração. Como resultado para os joelhos em varo: $46 \%$ de bons e ótimos resultados; $34 \%$ de regulares e $20 \%$ de resultados pobres, para os joelhos valgos: $41 \%$; $18 \%$ e $41 \%$ respectivamente.

Insall et al., 1984, publicam em um estudo prospectivo com 179 osteotomias tibiais valgizante em cunha de subtração e fixadas com gesso. Todas realizadas entre 1965 e 1976 no Hospital for Special Surgery. Com seguimento médio de 8,9 anos, $63 \%$ dos pacientes foram avaliados como bons e excelentes resultados, $9 \%$ como regular e $28 \%$ como resultado pobre. Enfatizam que o numero de maus resultados foram aumentando com o passar dos anos. 
Em 1976, Maquet propõe a técnica da osteotomia supracondilar femoral varizante com hipercorreção de 1 a 2 graus, com impacção do fragmento proximal sobre o distal, com fixação externa da osteotomia e carga imediata. Esta série de 37 joelhos apresenta resultados melhores do que seus resultados com a osteotomia tibial.

Alguns autores reservam as osteotomias para pacientes com idade inferior a 55-60 anos (Coventry, 1985). As osteotomias são consideradas por alguns autores como cirurgias temporárias, uma vez que com a evolução da osteoartrose há uma tendência à piora dos resultados clínicos e satisfação dos pacientes. Assim, o tratamento da osteoartrose com a osteotomia pode preceder em alguns anos o tratamento com a artroplastia.

Em 1987, Coventry apresenta um trabalho com 28 pacientes submetidos à osteotomia tibial em cunha de fechamento para as osteoartrose unicompartimentais em valgo, com um seguimento médio de 9 anos. Setenta e sete por cento dos pacientes apresentaram bons e excelentes resultados. Embora pouco usual, este autor refere vantagens nesta técnica.

Rudan \& Simurda, em 1990, publicam artigo prospectivo e avaliam os resultados clínicos e radiográficos de 79 osteotomias tíbias valgizantes em cunha de fechamento. Com um seguimento médio de 5,8 anos, o eixo mecânico fêmoro-tibial variou de 0 a $12^{\circ}$ de varo (média de $5,9^{\circ}$ ) para $2^{\circ}$ a 
$26^{\circ}$ de valgo (media de 9,1). O escore clínico variou de 62,1 para 83,3. Não foram encontradas diferenças estatísticas na função, arco de movimento, estabilidade e força do quadríceps.

Healy et al., 1988, publicam artigo com 21 pacientes ( 23 joelhos), seguimento médio de 4 anos, submetidos a osteotomia distal femoral. $\mathrm{O}$ ângulo fêmoro-tibial pré-operatório de 18 graus de valgo e pós-operatório de 2 graus de valgo. Oitenta e três por cento dos casos, de acordo com o escore do The Hospital for Special Surgery (HSS), obtiveram bons e excelentes resultados.

Em 1988, McDermott et al. chamam a atenção para angulação fêmorotibial (eixo mecânico) de zero grau e para a obliquidade articular após as osteotomia femorais, mas refere $92 \%$ de bons resultados em osteotomias supracondiliares.

Em 1988, Healy et al. descrevem detalhadamente uma série de 23 pacientes submetidos a osteotomia femoral, por via medial ou lateral, fixada com placa lamina de 90 graus. No parâmetro alinhamento obtiveram de 2-4 de valgo, exceto em um caso com super correção em varo. $O$ parâmetro função foi avaliado conforme o escore do HSS e variou de 65 no período pré-operatório para 86 no período pós-operatório. 
Em 1993, Edgerton et al. apresentam um estudo retrospectivo de 23 pacientes submetidos a osteotomia femoral supracondilar fixada com agrafes, com seguimento médio de 8,3 anos. Esses autores obtiveram $71 \%$ de bons e excelentes resultados, embora relatem que $13 \%$ das osteotomias tenham sido precocemente convertidas em artroplastia total do joelho. Em uma avaliação $75 \%$ dos pacientes operados referiam estarem satisfeitos com o procedimento cirúrgico.

O objetivo das osteotomias é corrigir a distribuição de cargas nos compartimentos medial e lateral do joelho, através da restauração do eixo fêmoro-tibial para valores fisiológicos de 5 a 10 graus de valgo. Este procedimento gera um novo alinhamento que proporciona melhora das queixas álgicas, pelo processo mecânico de redistribuição de cargas na articulação (Berman, et al.1991). Segundo este mesmo autor, as contraindicações absolutas da osteotomias são: osteoartrose bicompartimental, contratura em flexão do joelho maior que 15 graus, e contratura em adução do quadril. E a obesidade, insuficiência vascular ou arterial, e as doenças reumatológicas e ou inflamatórias seriam as de contraindicações relativas.

A melhora considerável da intensidade da dor é referida como principal motivo de satisfação dos pacientes submetidos às osteotomias. Alguns autores referem à diminuição da pressão intra-óssea como causa do alívio 
da dor (Akamatsu et al., 1997), melhora da mobilidade, retorno a atividades diárias e esportivas e melhora da qualidade de vida de modo geral.

Em 1996, Finkelstein et al. publicam um estudo retrospectivo onde avaliam a longevidade da osteotomia femoral com cunha de fechamento medial e fixada com placa de ângulo fixo como tratamento da osteoartrose em valgo. Demonstraram a redução dos resultados satisfatórios ao longo dos anos, de $83 \%$ de bons e excelentes resultados para $64 \%$ no período médio de 133 meses.

Em 1996, Nagel et al. publicam um estudo retrospectivo com 34 pacientes, todos homens, com idade média de 49 anos no momento da osteotomia tibial. Com um seguimento médio de 8 anos, comparam o nível de atividade físico-esportiva segundo a escala de Tegner \& Lysholm. Não se encontrou diferenças significantes nos níveis de atividade nos periodos pré e pós-operatório.

Morales et al., 2000, publicam artigo sobre osteotomia femoral varizante fixada com placa de ângulo fixo $\mathrm{AO}$ de 95 graus, com um seguimento médio de 6,5 anos relatam $75 \%$ de bons e ótimos resultados avaliados pelo score do HSS.

Em 2000, Aglietti et al. publicam um estudo com 18 pacientes, com idade média de 54 anos, e em seguimento médio de 9 anos, que apresenta 
$77 \%$ de bons e excelentes resultados de acordo com o Knee Society Score System.

Em 2002, Kassim et al. publicam artigo onde descrevem técnica cirúrgica para a osteotomia distal femoral varizante, com seguimento de 4 a 8 anos, e $71 \%$ a $83 \%$ de bons e excelentes resultados.

Em 2009, Andrade et al. em nosso meio, publicam trabalho retrospectivo com 15 pacientes submetidos a osteotomia femoral varizante em $\mathrm{V}$, fixada com placa de ângulo fixo. Com um seguimento médio de 81,4 meses, relatam $73 \%$ de excelentes e bons resultados e, $27 \%$ de regulares e ruins, levando em conta o escore KSS.

Em 2010, Zarrouk et al. apresentam um estudo retrospectivo de uma série de 20 pacientes (22 joelhos) submetidos à osteotomia distal e varizante do fêmur. Com seguimento médio de 54 meses, obtiveram $80 \%$ excelentes e bons resultados e $9,5 \%$ de resultados pobres. Com uma média do escore do IKS de 49,28 no pré-operatorio e de 72,85 no período pós-operatório.

$\mathrm{Na}$ literatura encontramos um bom número de autores que se sucedem com resultados semelhantes (Healy et al. 1988; Matthews et al.,1988; Zilber et al., 2004). A maioria deles refere à osteotomia femoral como uma técnica cirúrgica segura, e de grande valia para o tratamento da osteoartrose em valgo. Também há um consenso na literatura que os bons resultados 
diminuam com o aumento do seguimento. Ou seja, a conversão da ostetomia femoral em artroplastia total aumenta paulatinamente com os anos.

Puddu et al., em 2010, descrevem uma nova técnica para o tratamento dos joelhos com osteoartrose e desvios em varo e valgo. Nesta técnica, propõe-se que as osteotomias tibiais ou femorais devam ser realizadas com cunha de adição e fixadas com placa com calço de $7,5 \mathrm{~mm}$ a $15 \mathrm{~mm}$, desenvolvidas por estes autores. Tais placas promovem uma boa estabilização e permitem que o cirurgião avalie no intra-operatório o grau de correção atingido e quando não satisfeito, realize a troca da placa para uma maior ou menor. Estas osteotomias de cunha de abertura do lado lateral no fêmur e do lado medial na tíbia associadas às placas - calço proporcionaram novas perspectivas às osteotomias.

Wang \& Hsu em 2006, relatam em uma série de 30 pacientes com osteoartrose unicompartimental lateral submetidos à osteotomia femoral varizante fixada com placa angulada de 90 graus. Com um seguimento médio de 8 anos. Apresentam $83 \%$ de resultados satisfatórios, independentemente da artrose patelo-femoral grave, observada em 6 pacientes antes do procedimento cirúrgico. 
Em 2007, Puddu et al. publicam artigo onde utilizam a osteotomia femoral distal varizante em pacientes com osteoartrose lateral após meniscectomia ou com valgismo fisiológico acentuado.

De acordo com Franco et al. (2002), as indicações da osteotomia femoral são:

$\checkmark$ Paciente jovem ou meia idade;

$\checkmark$ Osteoartrose unicompartimental com mal alinhamento;

$\checkmark$ Deformidades adquiridas ou congênitas em valgo;

$\checkmark$ Osteonecrose do côndilo femoral lateral com valgismo;

$\checkmark$ Lesão condral do côndilo femoral associada a lesão aguda ou crônica do LCA/LCP;

E as contra-indicações são:

$\checkmark$ Arco de movimento limitado (menos do que 90 graus de flexão ou menos do que 15 graus de extensão);

Valgismo acentuado;

$\checkmark$ Paciente com artrite reumatóide;

$\checkmark$ Osteoartrose tricompartimental.

Em 2010, Kosashvili et al. publicam uma série de osteotomias femorais distais com um seguimento médio de 15 anos, houve uma redução 
significativa dos excelentes e bons resultados ao longo do seguimento, com uma taxa de falha com conversão para osteotomia de $48,5 \%$.

\subsection{Cirurgia ortopédica e a navegação}

A cirurgia ortopédica assistida por computador - computer aided orthopedic surgery (CAOS), já tem sido largamente discutida nas artroplastias de joelho e quadril, nestes procedimentos advoga-se que o navegador forneça dados precisos para o posicionamento inequívoco dos componentes protéticos e alinhamento adequado dos membros. Desta forma, o cirurgião pode durante $o$ ato operatório confirmar o alinhamento final do membro, melhorando a sobrevida dos implantes e resultado em longo prazo.

Em 1998, DiGioia et al. publicam artigo descrevendo técnicas de cirurgia ortopédica assistida por diversas técnicas de navegação, ressaltando suas vantagens, limitações e futuras tendências como a cirurgia robótica. A necessidade de melhorar os resultados clínicos das cirurgias ortopédicas justifica a busca constante de novas tecnologias

Ainda em 1998, Taylor et al. defendem o uso de novas ferramentas, como os navegadores, na rotina clínica (hospitalar), embora isto cause 
inicialmente a resistência e o desconforto de alguns cirurgiões. Esta integração é necessária e inevitável.

Stulberg et al., em 2000, descrevem com detalhes a técnica cirúrgica da artroplastia total de joelho assistida por computador, advogam suas vantagens em relação à técnica tradicional, e a possibilidade de alcançar um eixo mecânico exato.

Em 2000, Morales et al. publicam artigo sobre osteotomia femoral varizante fixada com placa de ângulo fixo $A O$ de 95 graus, com um seguimento médio de 6,5 anos relatam $75 \%$ de bons e ótimos resultados avaliados pelo score do HSS.

Amiot et al. (2004) descrevem técnicas de cirurgias ortopédicas com o uso da navegação auxiliada por tomografia.

Albuquerque et al. (2006) publicam um estudo com 68 pacientes submetidos à artroplastia total do joelho. Estudaram 72 artroplastias em 49 mulheres e 19 homens, com a utilização do navegador "OrthoPilot", versão 2.2 da Aesculap, obtiveram um desvio médio do eixo mecânico nulo de 0,66 , sendo que $98,6 \%$ dos joelhos ficaram dentro da margem de erro de 3 graus. 
Hankemeier et al. (2006) em um estudo em cadáveres, comparam as vantagens e as desvantagens do uso da navegação nas osteotomias. Evidenciam a precisão na determinação do eixo mecânico nestas cirurgias e sua importância para o resultado clínico em longo prazo.

Em 2010, Hankemeier et al. publicam artigo no qual validam a osteotomia tibial com cunha de abertura e navegada em cadáveres, e discorrem sobre suas vantagens e desvantagens em relação a técnica convencional.

Em 2007, Sastre et al. apresentam relato de caso descritivo da cirurgia de osteotomia femoral do joelho com auxílio de navegação assistida por artroscopia e auxiliada por radioscopia neste trabalho utilizou-se o navegador "Stryker-Howmedica navigation software" , o mesmo utilizado em nosso estudo.

Em 2007, Siston et al. advogam o uso dos navegadores como ferramenta de melhora das habilidades cirúrgicas e da busca constante de resultados mais precisos.

Em uma metanálise sobre a artroplastia total de joelho assistida por navegador, Mason et al. (2007) revisam 511 artigos e utilizam 22 trabalhos como referência. Nesta metanálise nos parâmetros: alinhamento no eixo 
mecânico e posicionamento dos componentes protéticos houve uma vantagem estatisticamente significante quando a navegação é utilizada.

Em 2008, Song et al. em um artigo de revisão discutem as dificuldades de obter o alinhamento ideal durante a osteotomia tibial e fazem referência ao impreciso "método do cabo" como o recurso utilizado por muitos ortopedistas antes da navegação. Evidenciam as vantagens intra operatórias do uso dos navegadores como informações precisas da correção angular realizada.

Rosenberger et al. (2008) publicam estudo prospectivo de 50 casos submetidos a artroplastia total de joelho com auxílio da navegação comparados com 50 casos com a técnica convencional. Avaliaram posicionamento final dos componentes protéticos e alinhamento do membro inferior.

Salzmann et al., em 2009, estudam uma série de pacientes submetidos à osteotomia tibail varizante e o nível de atividade esportiva após este procedimento. Com um seguimento médio de 36 meses, e uma média de idade de 41,2 anos no momento da cirurgia. Neste grupo $87,9 \%$ dos pacientes referiam a realizar algum tipo de atividade física em torno de 2 vezes por semana. 
Em 2012, Saragaglia et al. publicam artigo prospectivo com 42 pacientes com idade menor que 65 anos e osteoartrose grave em varo, submetidos a osteotomias simples (tibial) ou duplas( tibial e femoral) com o auxilio do navegador (OrthoPilot). Com um seguimento médio de 46 meses, obtém $92,7 \%$ de sucesso radiográfico $(181,83+-1,80)$.

Iorio et al., 2013, em um estudo prospectivo e comparativo, confrontam 13 casos de osteotomia tibial navegada (OrthoPilot; B.Braun Aesculap, Tuttlingen, Germany) com cunha de abertura e fixada com placa-calço de apoio, com 11 casos de osteotomia pelo método convencional. Clinicamente, não houve diferença estatística entre os grupos.

\subsection{Osteotomia femoral e navegação}

A osteotomia femoral por navegação tem como objetivo fornecer ao cirurgião dados mais precisos durante o procedimento cirúrgico para que o alinhamento final desejado seja exatamente aquele planejado, aumentando assim a expectativa dos bons resultados em longo prazo. Uma vez que um dos fatores para um mal resultado em curto prazo é a sub-correção ou super- correção angular da deformidade. Realizar a osteotomia de maneira precisa é o ponto chave das osteotomias. 
Em 2000, Puddu \& Franco descrevem com detalhes a técnica operatória para as osteotomia femoral varizante fixada com uma placa-calço, e descrevem alguns critérios de elegibilidade para este procedimento:

$\checkmark$ Deformidade congênita com valgo menor que $15^{\circ}$;

Deterioração da cartilagem após meniscectomia lateral;

$\checkmark$ Artrose unicompartimental lateral;

$\checkmark$ Alteração do osso subcondral à ressonância magnética com valgismo discreto.

A osteotomia femoral é uma técnica que exige planejamento prévio cuidadoso e execução precisa. Há uma longa lista de possíveis complicações descritas: infecção, pseudoartrose, quebra de material de síntese, perda da correção, rigidez articular (Puddu et al., 2007).

A frequência das complicações depende da técnica utilizada e da experiência da equipe em executá-la.

O posicionamento radiográfico final do membro tem influência direta nos resultados clínicos e na longevidade da cirurgia.

Em 1995, Chao \& Sin desenvolvem um algoritmo que utiliza um programa de computador interativo no qual o cirurgião pode encontrar uma "correção ótima" para futura osteotomias, seja femoral, tibial ou dupla. Com o objetivo de prolongar os benefícios da osteotomia, levando em 
consideração: o alinhamento mecânico, a distribuição de cargas e a obliquidade da articulação.

Saragaglia et al., em 2005, apresentam em relato de 170 osteotomias, sendo 135 tibiais, 24 femorais e também 11 osteotomias duplas (tibial e femoral) nos casos de grande deformidade, com mais de $96 \%$ de bons resultados. Todas as osteotomias foram realizadas com o auxílio do navegador.

Maurer \& Wassmer (2006) publicam artigo onde comparam os resultados de dois grupos de osteotomias: um grupo com a utilização do navegador e outro coma técnica convencional. Seus resultados indicam uma clara vantagem do grupo com navegação no parâmetro alinhamento.

Em 2006, Verheyen publica um relato de caso de um paciente de 17 anos de idade com deformidade proximal femoral grave submetido à osteotomia corretiva com o uso da navegação, defendendo seu uso nos casos de grande deformidade e de difícil correção.

Kendoff et al., 2007, em estudo com cadáveres e com um navegador cirúrgico, questionam e testam a influência das rotações (interna e externa) do membro inferior e da extensão total e das flexões em 5, 10 e 20 graus na informação do alinhamento do eixo mecânico. Não houve diferença estatística nos joelhos fixos em rotação interna ou externa. Em contra 
partida, durante as flexões de 5, 10 e 20 graus, houve diferença significante em todas as medidas.

Lorenz et al., 2007, apresentam e discutem técnica cirúrgica da osteotomia com o auxílio do navegador (Vector Vision System-Brainlab). Descrevem passo a passo o procedimento cirúrgico desde o planejamento pré-operatório criterioso até a fixação com placa da osteotomia.

Torner et al., 2008, publicam trabalho com relato de três casos no qual advogam o uso do navegador para os casos de grande deformidade óssea, sequela de fratura ou deformidade congênita passíveis de correção por osteotomia femoral, tibial ou dupla. Consideram o navegador como uma ferramenta bastante útil e uso rotineiro, com mais de 200 casos operados.

Em 2010, Kendoff et al. apresentam um relato de caso no qual utilizam o navegador para auxiliar no procedimento cirúrgico de um paciente que apresentou fratura femoral periprotética consolidada em varo, após artroplastia total de joelho.

Pearle et al. (2009) discutem a confiabilidade e reprodutibilidade do uso dos navegadores durante os osteotomias em cadáveres; comparando os valores pré-operatórios do navegador com valores pós-operatórios obtidos por tomografia computadorizada com reconstrução em três dimensões. Neste estudo, observou uma grande precisão entre as medidas no plano 
coronal entre o navegador e a tomografia (pós-operatório), porém uma precisão pobre no que refere ao plano sagital, inclinação do platô tibial. 
4. Métodos 


\section{MÉTODOS}

O presente estudo foi realizado no Hospital Geral de Pedreira-OSS e no ambulatório dos Jardins dos Prados e recebeu aprovação da Comissão de Ética para Análise de Projetos de Pesquisa (CAPPesq) do Hospital das Clínicas da Faculdade de Medicina da Universidade de São Paulo, sob o número 0265/09.

\subsection{Casuística}

Vinte e cinco (25) pacientes com osteoartrose lateral do joelho com menos de 55 anos, com queixas álgicas e com deformidade em valgo maior que 9 graus.

Estes pacientes após exames clínicos pré-operatórios foram divididos em 2 grupos.

Treze (13) pacientes - grupo estudo - com osteoartrose lateral, deformidade em valgo e com queixas álgicas foram avaliados pré e pósoperatório em relação ao nível de atividade, dor e instabilidade segundo a escala da Knee Society Scoring System (Ewald, 1989; Insall et al.,1989), 
com validação para o português (Silva et al., 2012).

Doze (12) pacientes - grupo controle - com as mesmas características clínicas serão submetidos ao procedimento convencional (sem a utilização do navegador). Todos os pacientes foram operados pelo mesmo cirurgião.

Estes pacientes foram submetidos à osteotomia femoral varizante, com cunha de abertura lateral e fixada com a placa de ângulo fixo com parafusos bloqueados. Durante o procedimento cirúrgico, a abertura da cunha é acompanhada pelo o navegador e quando houver a informação de 0 grau no eixo mecânico, a cunha é estabilizada com uma placa.

O desenho inicial do presente estudo contemplava 40 pacientes sendo 20 pacientes para cada técnica, por dificuldades técnicas diversas encerramos o estudo com casuística apresentada.

4.2 Critérios de inclusão

1. Pacientes com osteoartrose unicompartimental lateral;

2. Idade entre 20 e 55 anos;

3. Desvio em valgo do eixo mecânico maior ou igual a 10 graus;

4. Não apresentar contratura em flexo; 
5. Apresentar arco de movimento do joelho maior que 90 graus;

6. Não ter sido submetido à cirurgia ortopedia no joelho acometido;

7. Ter assinado o termo de Consentimento Livre e Esclarecido (formulado obedecendo às recomendações da Resolução № 196 de 10 de outubro de 1996 do Conselho Nacional de Saúde), declarando ter compreendido todas as explicações e ter concordado plenamente com a pesquisa.

4.3 Critério de exclusão

1. Desistência do paciente a qualquer momento da pesquisa;

2. Presença de qualquer doença sistêmica descompensada ou que impedisse a realização da cirurgia;

3. Ter realizado cirurgia ortopédica nos membros inferiores;

4. Óbito do paciente.

4.4 Análise estatística

Para avaliar os resultados entre a cirurgia convencional e navegada, utilizamos o teste de Mann Whitney, com objetivo de preservar o poder do 
estudo. As variáveis que serão verificadas para diferença estatística entre os grupos são: idade, tempo de cirurgia, tempo de garrote, alinhamento do membro e escore do KSS.

A variável alinhamento pós foi categorizada com as margens de erro acima de $\pm 2^{\circ}$ e $\pm 3^{\circ}$ de alinhamento e comparados pelo Teste Exato de Fisher para diferença estatística entre os grupos.

Com objetivo de verificar a correlação entre o alinhamento inicial e final por tipo de cirurgia, aplicamos a Correlação de Spearman. Valores de $p$ menores que 0,05 foram considerados como estatisticamente significantes.

Para análise estatística utilizamos o programa STATA versão 12.1 (Copyright StataCorp Lakeway Drive College Station, Texas, USA).

\subsection{Técnica cirúrgica}

O paciente é encaminhado ao centro cirúrgico e na sala de "préanestesia" recebe uma dose de cefuroxima $1,5 \mathrm{~g} \mathrm{EV}$, é submetido à tricotomia e ao preparo do membro inferior a ser operado, conforme protocolo do Hospital Geral de Pedreira. 
O paciente sorteia a qual técnica cirúrgica será submetido, retirando de um envelope um número: zero (técnica convencional); um (técnica com navegação).

Se a técnica convencional for sorteada, este paciente não será submetido ao tempo cirúrgico da navegação, sendo o restante do procedimento semelhante.

Após a anestesia do paciente, realiza-se a assepsia do membro a ser operado com clorexidine ou polvedine. Posicionamento de garrote pneumático e campos estéreis são colocados.

\subsubsection{Navegação}

Somente os pacientes do grupo navegação serão submetidos a este tempo cirúrgico.

Com o paciente em decúbito dorsal horizontal, medialmente a tíbia e lateralmente ao fêmur, são posicionados dois pequenos fios de Steimann para a fixação dos "trackers" - instrumentos de orientação, que emitem sinais de infravermelho (IV) ao navegador que está posicionado ao lado da maca cirúrgica. 


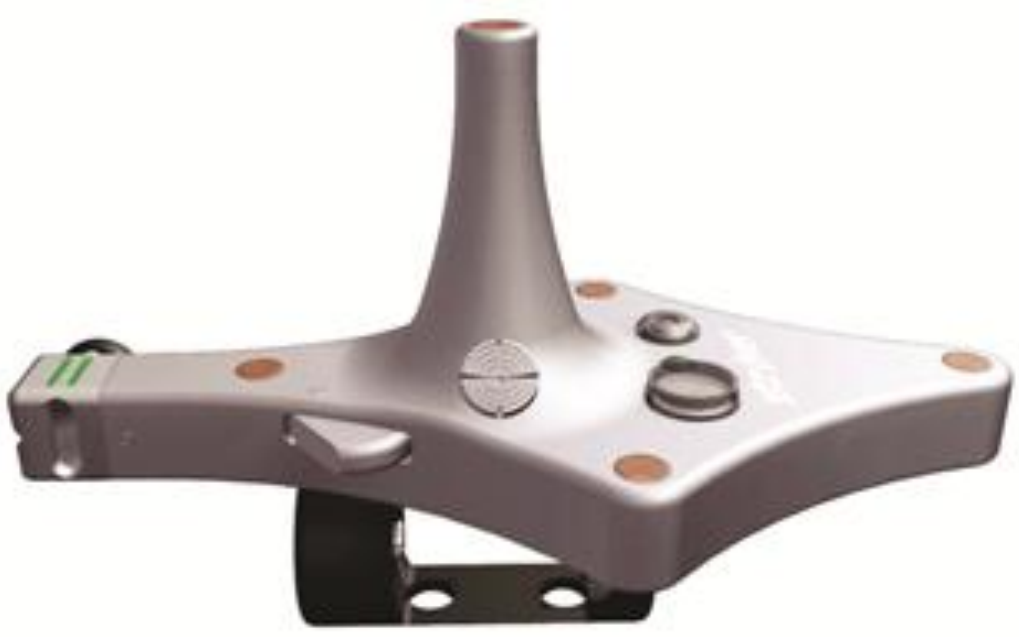

Figura 1. Fotografia do "Tracker"

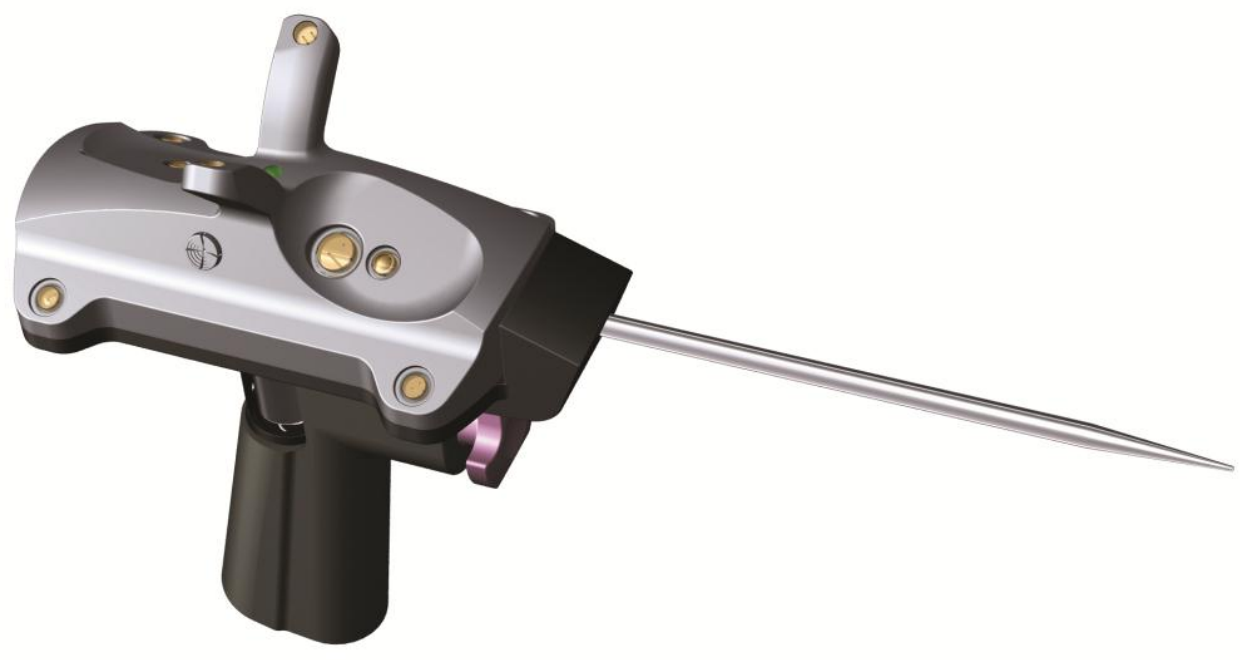

Figura 2. Fotografia do "Pointer"

Com o auxílio do "pointer" - instrumento móvel de marcação de pontos anatômicos- determinados pontos de referência do fêmur distal e da tíbia proximal e distal são informados ao navegador. 


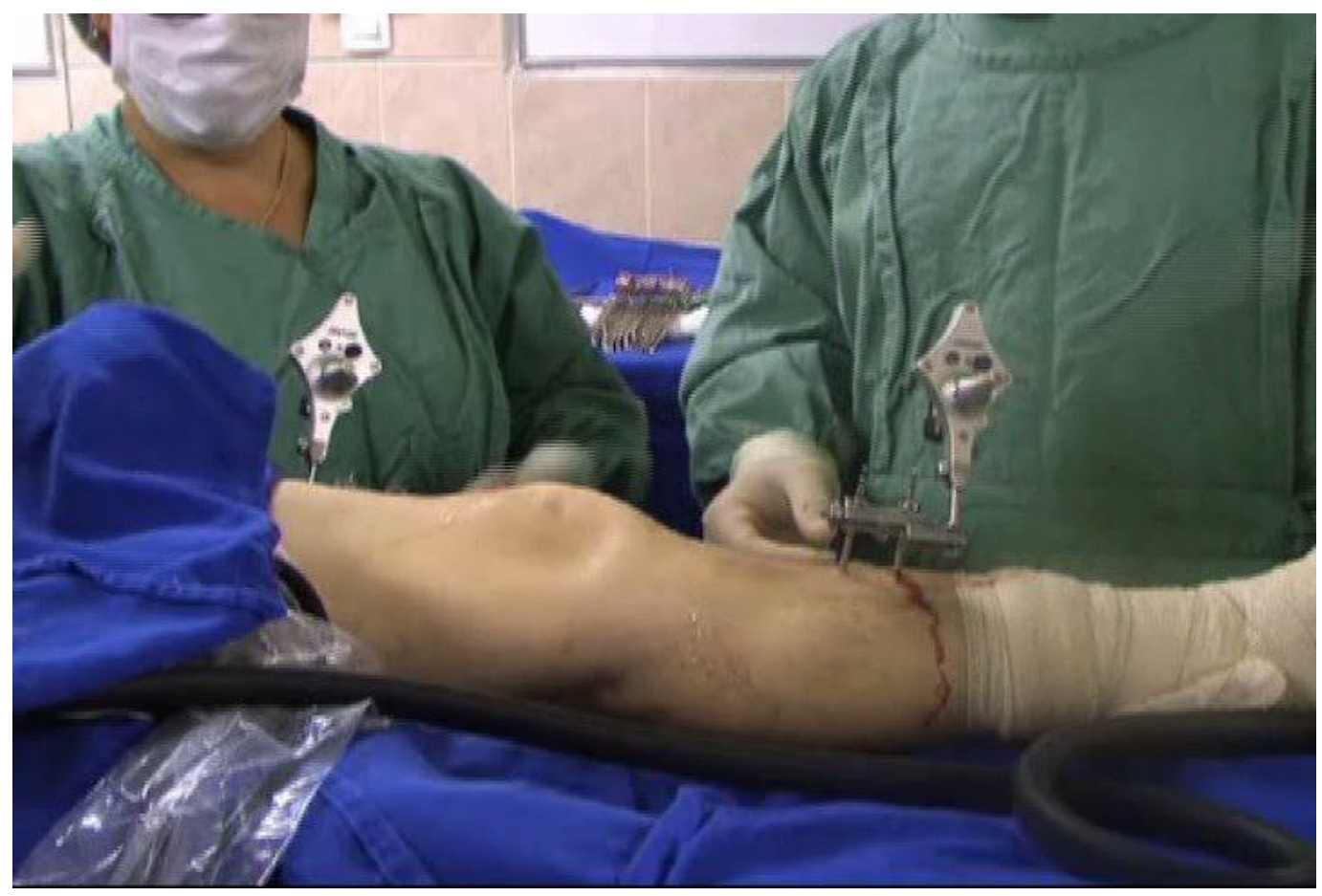

Figura 3. Membro inferior com "Trackers" posicionados

Este mensura e informa, através de um monitor, qual o "status" atual do eixo mecânico do membro do paciente, durante o decorrer do procedimento cirúrgico. 


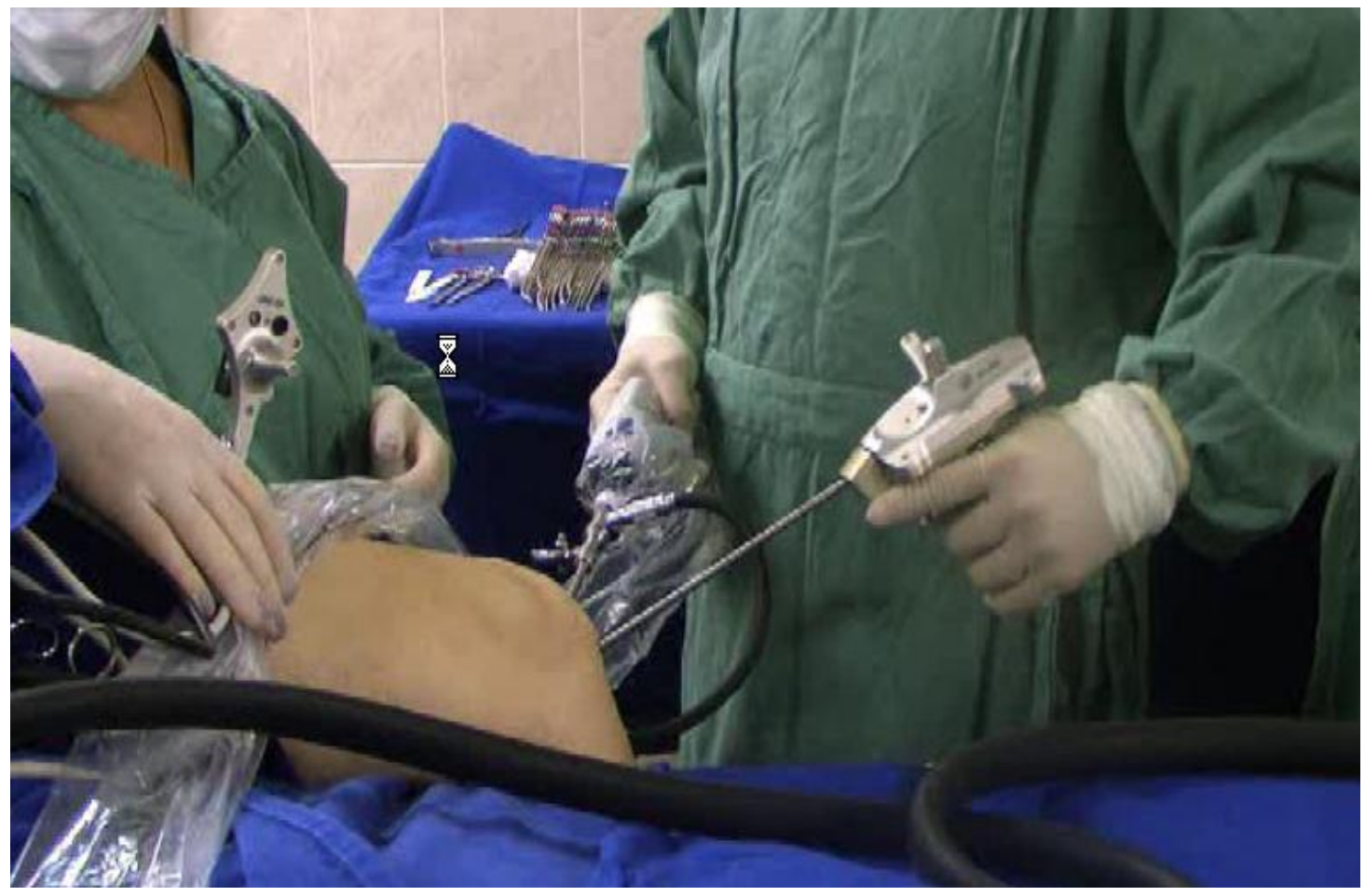

Figura 4. Alimentação do navegador através da artroscopia

O navegador utilizado neste projeto é o Stryker-howmedica versão 4.0 com software para osteotomia, que utiliza os seguintes pontos de referência anatômicos: centro de rotação do quadril, epicôndilo medial e lateral do joelho, eixo ântero-posterior do fêmur, eixo ântero-posterior da tíbia, maléolo medial e lateral do tornozelo. Estes pontos são informados por orientação visual direta pela palpação dos mesmos com "pointer" acoplado a um dos transmissores IV, na sequência padronizada pelo navegador.

O centro do quadril é calculado pelo software pelo acompanhamento da manobra de rotação do mesmo, realizada manualmente pelo cirurgião. 


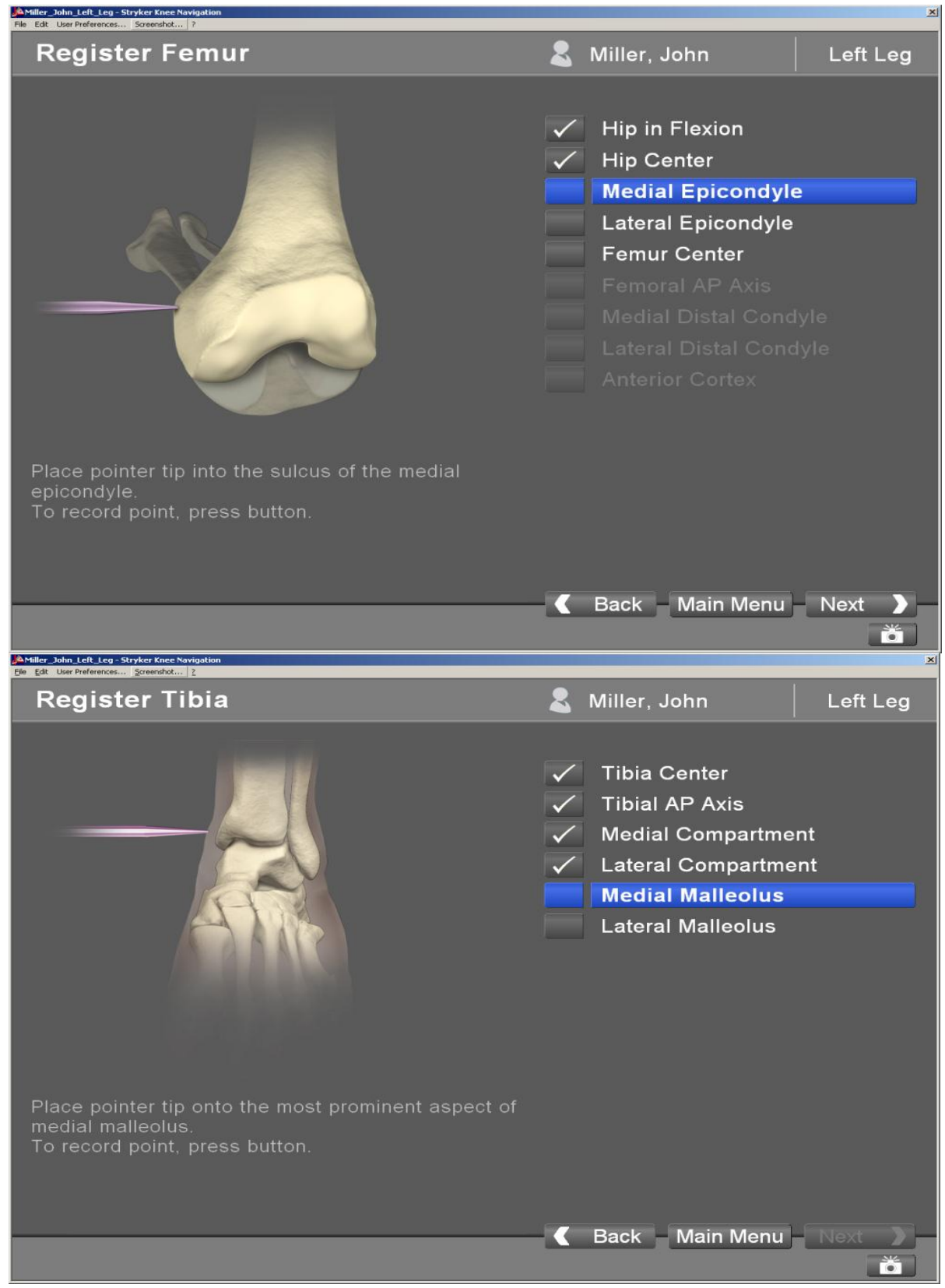

Figura 5. Imagem do navegador "solicitando" os pontos anatômicos de referência (epicôndilo medial e maléolo medial) 


\subsubsection{Artroscopia}

A artroscopia é realizada através dos portais infrapatelares medial e lateral. Utilizamos o vídeo artroscópio do Hospital Geral de Pedreira que utiliza: ótica de 4,5 mm e monitor HD de 32 polegadas.

A artroscopia neste procedimento tem a finalidade de: alimentar 0 navegador com as informações solicitadas por ele. Ou seja, alguns pontos intra-articulares serão palpados através da artroscopia: côndilo medial, côndilo lateral, platô tibial medial e lateral, eixo ântero-posterior da tíbia e do fêmur.

\subsubsection{Osteotomia femoral}

A incisão é realizada na região lateral do joelho da região do epicôndilo lateral do fêmur proximalmente por aproximadamente por $15 \mathrm{~cm}$.

Pele, subcutâneo são dissecados a fáscia muscular é seccionada longitudinalmente. O músculo vasto lateral é deslocado para cima, sem seccioná-lo. 


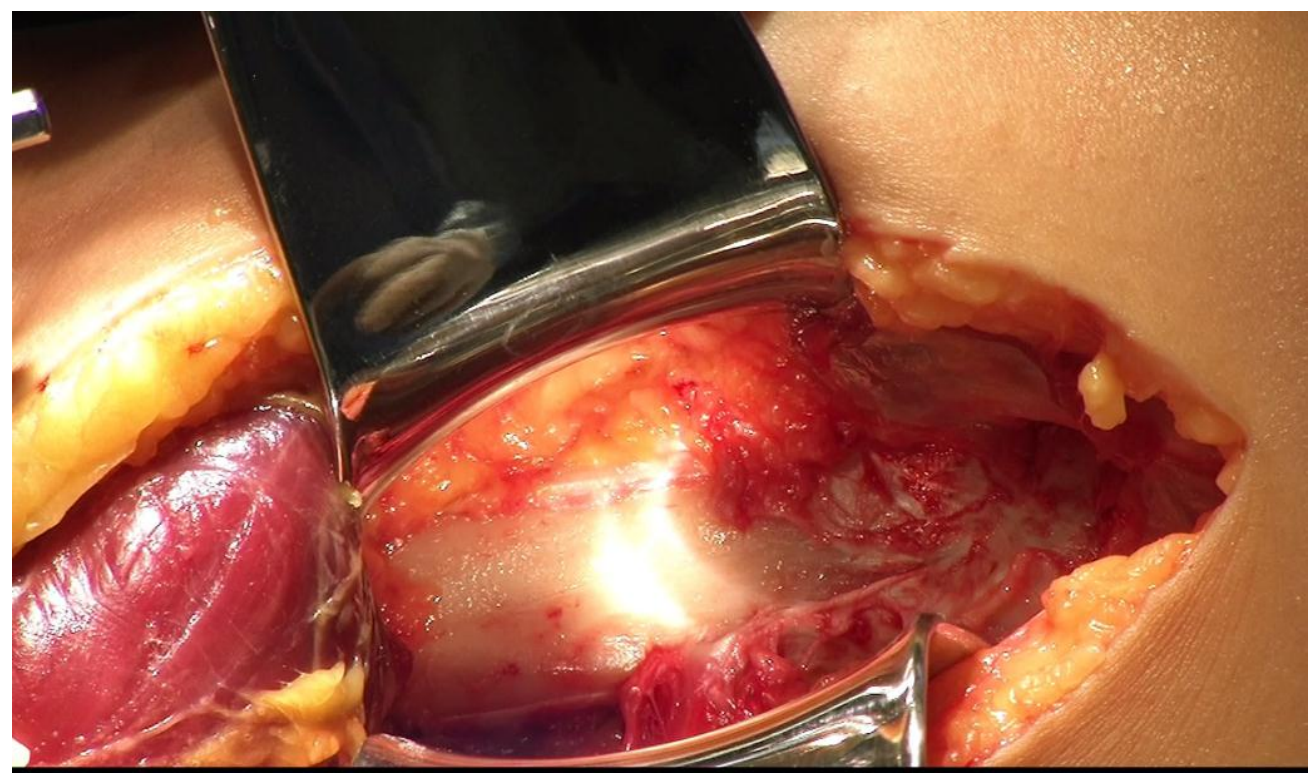

Figura 6. Fotografia da via de acesso lateral (músculo vasto lateral devulcionado superiormente). Identifica-se a cortical lateral do fêmur

A osteotomia femoral é realizada com o auxílio da radioscopia de acordo com a técnica de Puddu, na qual são introduzidos um fio de Kirchner paralelo a articulação aproximadamente $1 \mathrm{~cm}$ acima dela, e mais 2 fios são introduzidos obliquamente de medial para lateral formando um ângulo aproximadamente de 45 graus. 


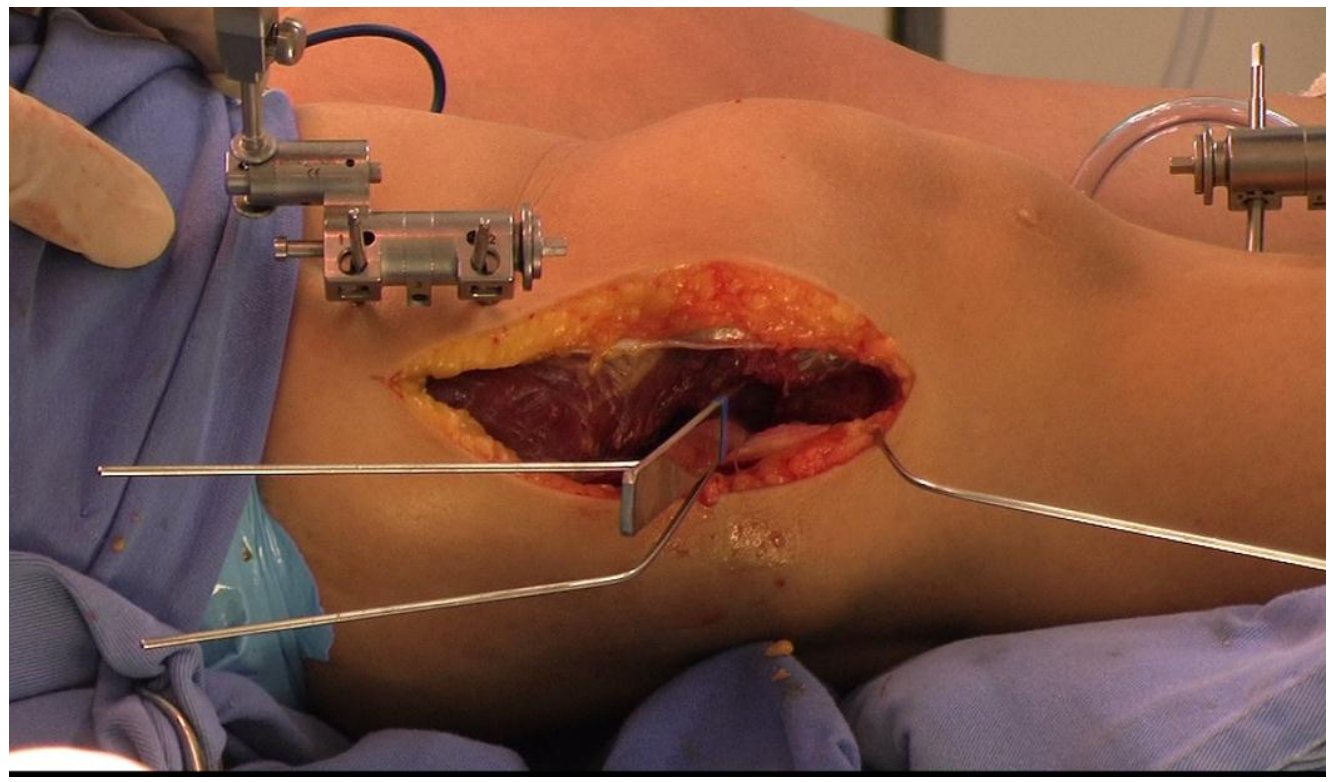

Figura 7. Fotografia do fêmur distal com 3 fios e osteótomo

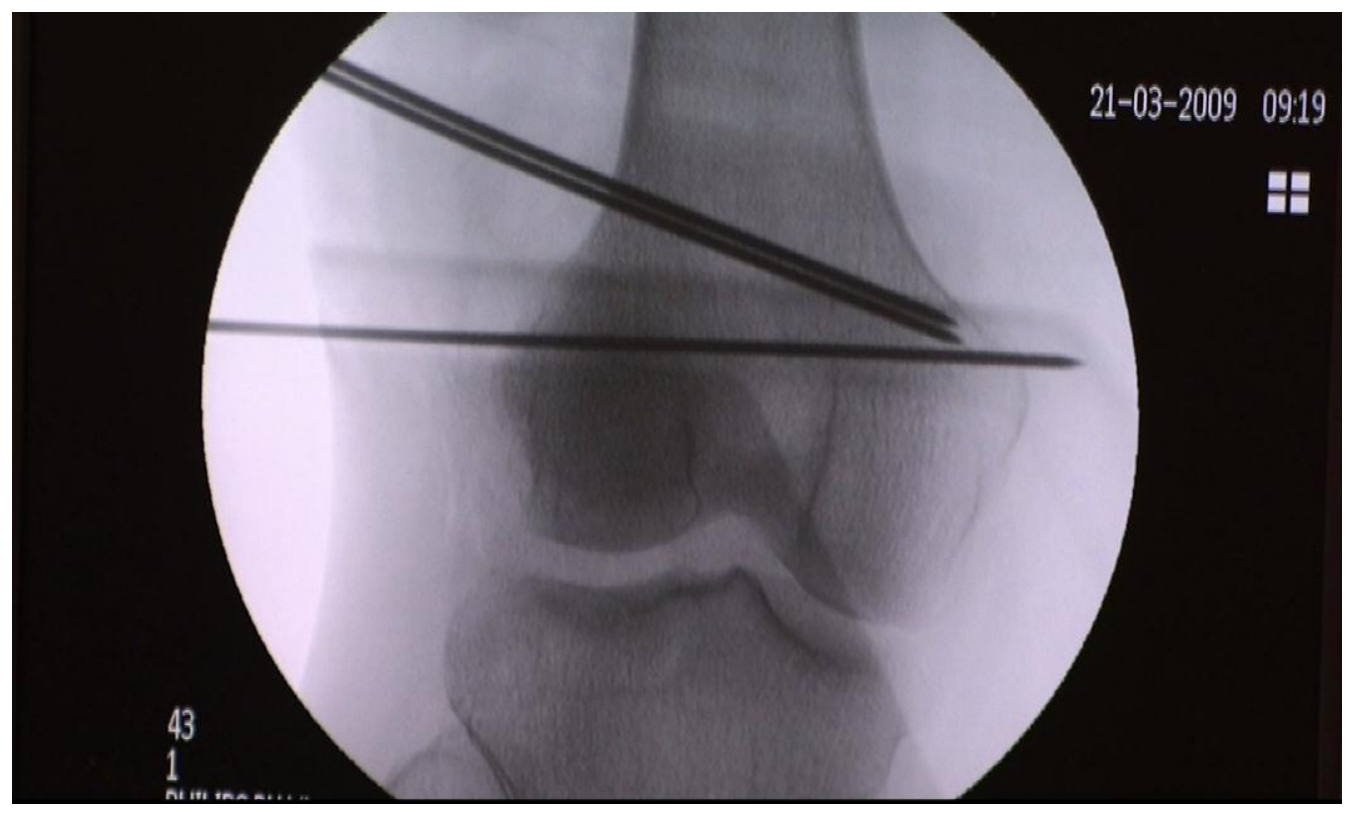

Figura 8. Imagem de radioscopia onde se identifica o fêmur distal e o posicionamento dos três fios de Kirchner 
A osteotomia é realizada com serra oscilante e osteótomo, obliquamente sob visão radioscópica sem romper a cortical medial, sendo paulatinamente aberta com o uso de osteótomo ou instrumento similar.

Neste tempo, toma-se muito cuidado para não quebrar a cortical medial do fêmur, uma das complicações mais frequentes e desastrosas neste procedimento.

Durante este tempo cirúrgico, o navegador informa em tempo real as alterações sofridas no eixo mecânico.

Quando a correção angular atinge o eixo mecânico desejado, ou seja, zero grau a cunha de abertura formada é fixada com a placa Ao Tomofix®.

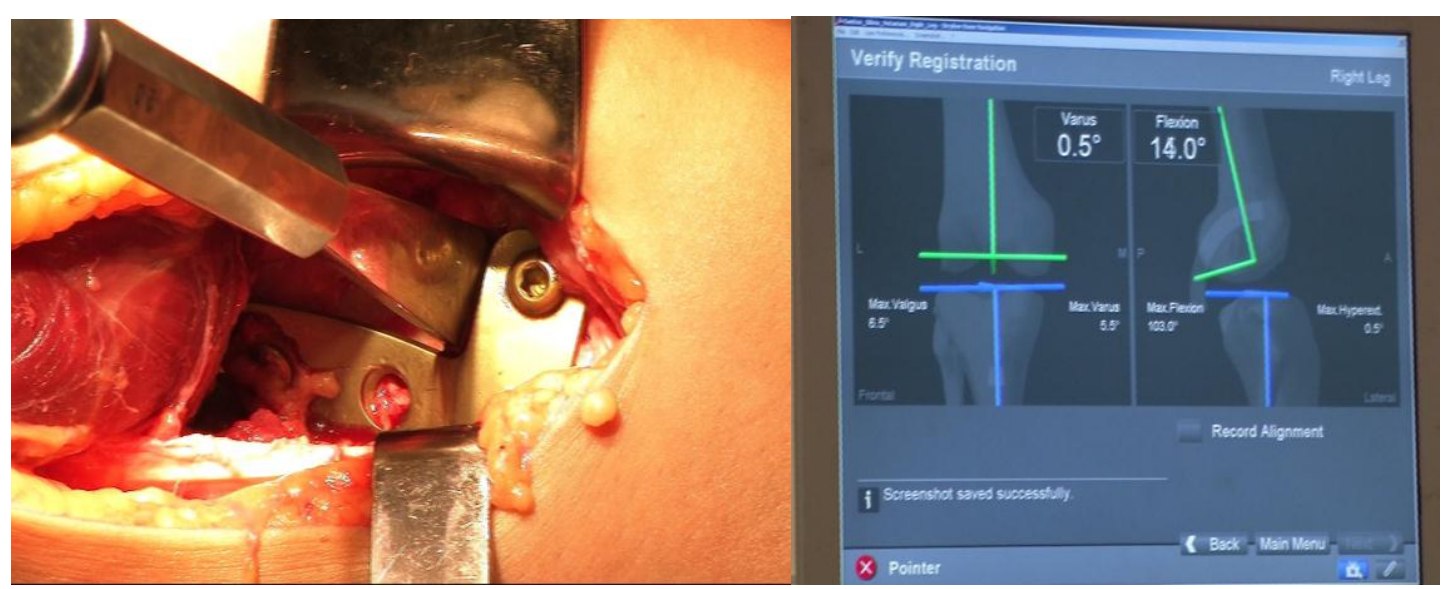

Figura 9. Fotografia do fêmur distal no momento da fixação da placa, ao mesmo tempo, orientação do alinhamento pelo navegador 
Após a fixação da placa no fêmur, os planos: muscular, fascial, subcutâneo são suturados com "vycril"1.0 e a pele é suturada com "nylon"4.0. O garrote pneumático é liberado. Um dreno de sucção é instalado. Após o curativo com gaze e enfaixamento, utilizamos imobilizador removível.

O procedimento pós-operatório foi o mesmo para os dois grupos: analgesia com anti-inflamatórios e opiódes, antibioticoterapia (cefuroxima 1,5g EV 12/12hs por 24hs) e profilaxia contra trombose venosa (enoxaparina sódica 40mg, SC) por 21 dias.

No período pós-operatório iniciou-se movimentação passivo-assistida precocemente nas primeiras 24 horas, porém sem carga, e deambulação com muletas axilares, por 6 ou 8 semanas. Somente após este período, permitimos o apoio parcial se houver imagem radiográfica demonstrando a presença de calo ósseo. 


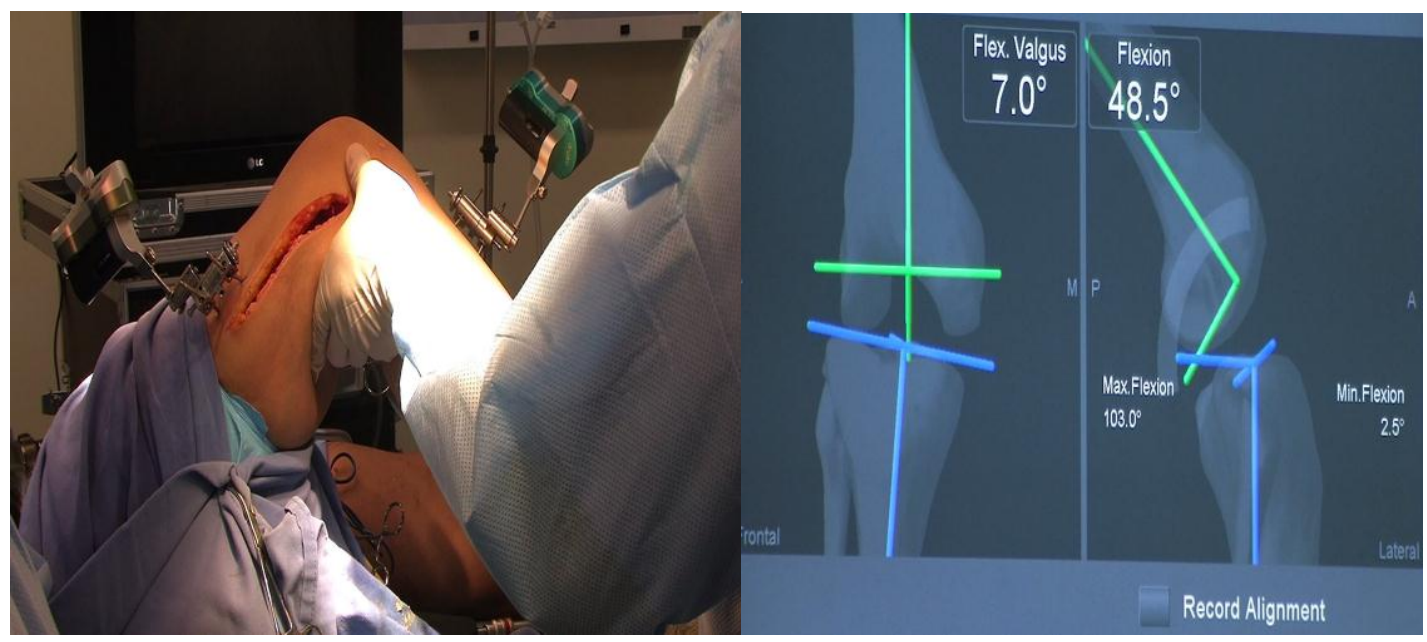

Figura 10. Após a fixação da placa verifica-se: o ADM do membro, e o alinhamento pelo navegador

Os pacientes receberam alta hospitalar no segundo dia pós-operatório se estivessem clinicamente estáveis.

O acompanhamento médico ambulatorial e fisioterápico acontecerá com retornos semanais ao ambulatório de ortopedia e três vezes por semana no serviço de fisioterapia. 


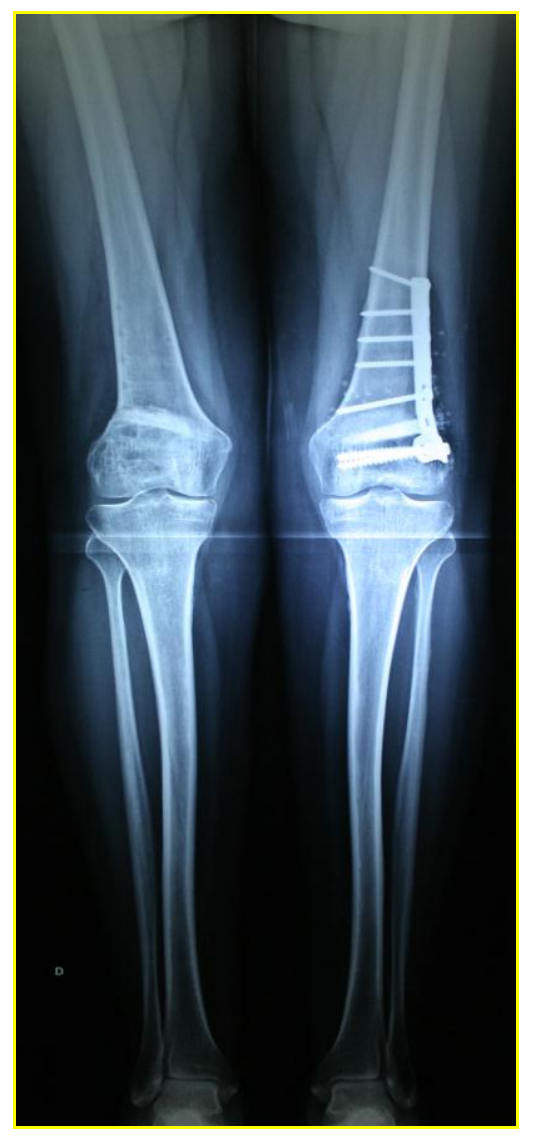

Figura 11. Radiografia dos mmii demonstrando o eixo

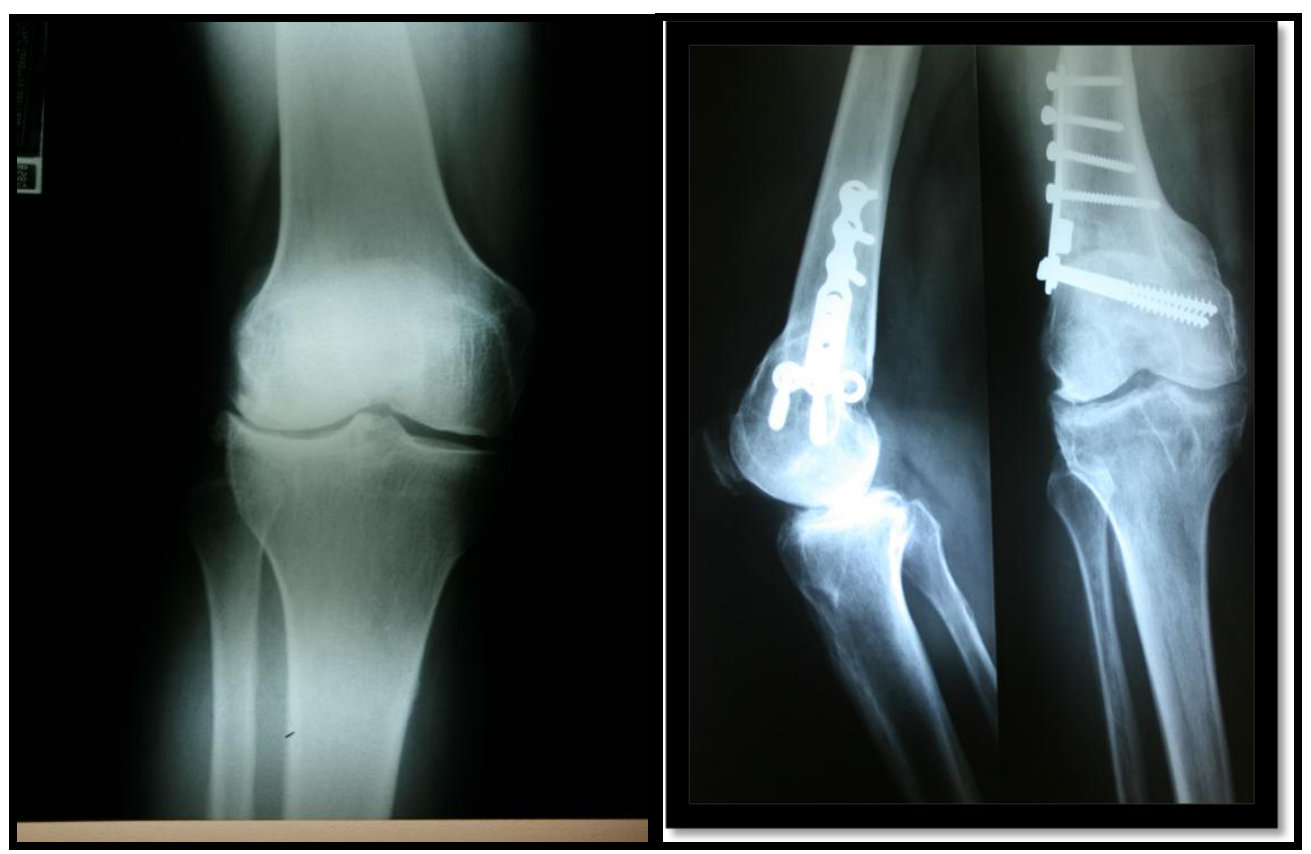

Figura 12. Radiografia em AP e P de joelho, aspecto pré e pós-operatório de osteotomia femoral 


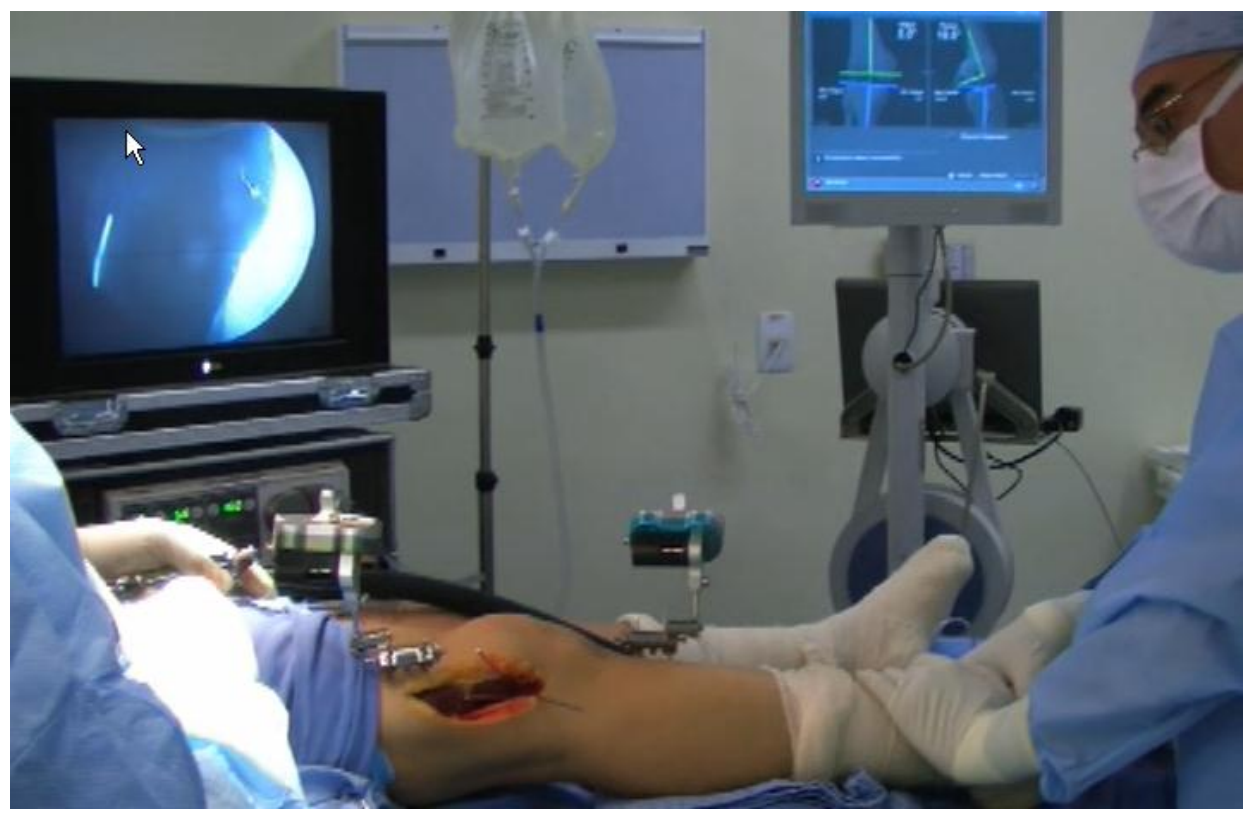

Figura 13. Fotografia da sala cirúrgica, durante ato operatório

\subsection{Avaliação pós-operatória}

Todos os pacientes foram acompanhados e avaliados no Serviço de Ortopedia do Ambulatório de Especialidades do Hospital Geral de Pedreira.

Após 6 meses de procedimento cirúrgico, eles respondiam ao questionário do escore do HSS com validação para o português. E eram avaliados radiograficamente com radiografias que incluíam o quadril e 0 tornozelo. Media-se o eixo mecânico (Figura 14). 


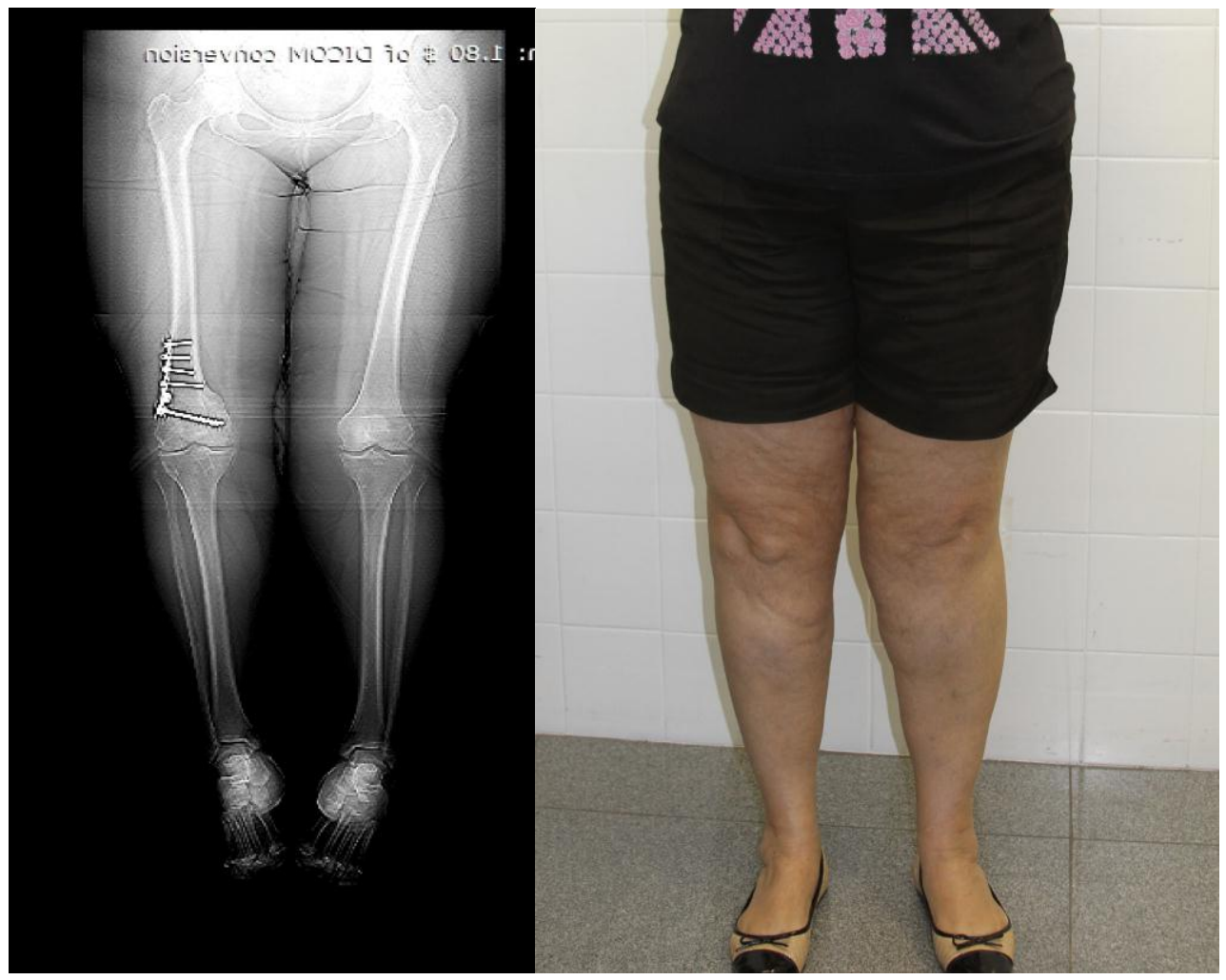

Figura 14. RX e imagem pós-operatória 
5. Resultados 


\section{RESULTADOS}

No total foram analisados 25 pacientes, $48 \%$ do sexo masculino e $52 \%$ feminino. A idade variou de 39 a 55 anos, sendo a média de 50,08 com desvio padrão de 3,93 anos.

Gráfico 1 - Histograma de Idade por grupos (submetidos à cirurgia com uso de navegação e pela técnica convencional)

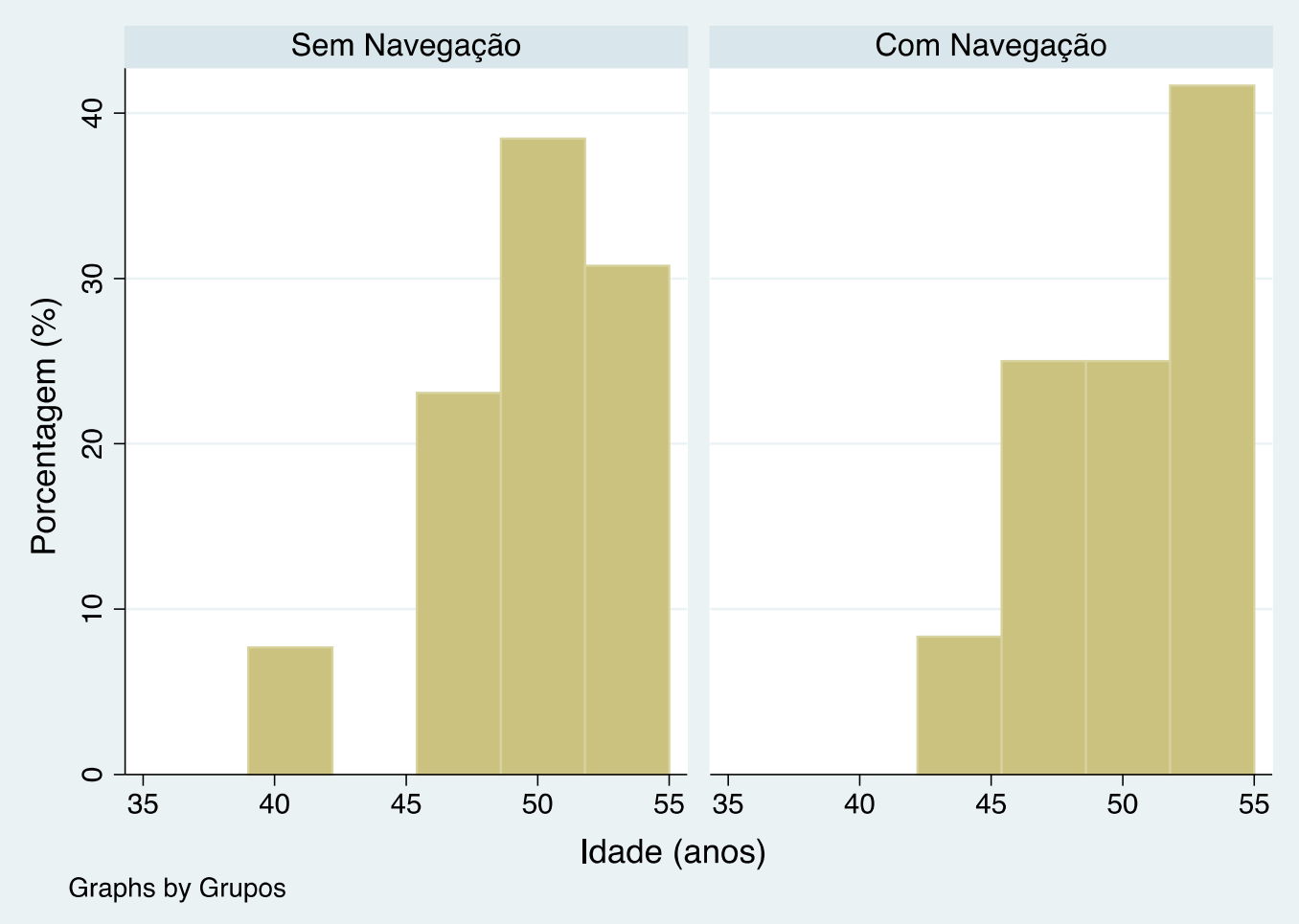

Os grupos foram divididos entre: pacientes submetidos à osteotomia por técnica convencional ( $n=13$ pacientes) e, por navegação computadorizada ( $\mathrm{n}=12$ pacientes). Para diferença estatística, os grupos foram comparados pelo Teste de Mann-Whitney para as variáveis 
numéricas, devido a variabilidade das variáveis. Na tabela abaixo, observamos as características da amostra entre os grupos. A idade entre os indivíduos em ambos os grupos foi semelhante devido ao critério de inclusão, porém observamos um maior número de indivíduos acima de 50 anos no grupo com uso de navegação.

Tabela 1 - Distribuição entre os grupos

\begin{tabular}{|c|c|c|c|c|c|c|}
\hline & \multicolumn{2}{|c|}{$\begin{array}{l}\text { CONVENCIONAL } \\
\qquad(\mathrm{n}=13)\end{array}$} & \multicolumn{2}{|c|}{$\begin{array}{c}\text { GUIADA POR } \\
\text { NAVEGAÇÃO } \\
(n=12)\end{array}$} & \multirow[b]{2}{*}{ IC 95\% } & \multirow[b]{2}{*}{$P$} \\
\hline & Média & DP & Média & DP & & \\
\hline Idade & 49,5 & 4,13 & 50,66 & 3,79 & $48,45-51,7$ & 0.5280 \\
\hline \multicolumn{7}{|c|}{$\operatorname{Sexo}(n / \%)$} \\
\hline Masculino & 6 & 46,15 & 6 & 50,0 & - & - \\
\hline Feminino & 7 & 53,85 & 6 & 50,0 & - & - \\
\hline $\begin{array}{l}\text { Tempo de } \\
\text { cirurgia }\end{array}$ & 73,69 & 12,53 & 92,75 & 16,49 & $75,71-89,9$ & 0.0046 \\
\hline $\begin{array}{l}\text { Tempo de } \\
\text { garrote }\end{array}$ & 59 & 7,02 & 68,16 & 10,88 & $59,2-67,5$ & 0.0237 \\
\hline
\end{tabular}


O tempo de cirurgia foi estatisticamente diferente entre as técnicas utilizadas $(p=0.0046)$ com média (desvio padrão) de 73,69 m $(12,53)$ para a técnica convencional e 92,75m $(16,49)$ quando utilizada a técnica com navegação. Consequentemente, o tempo de garrote pneumático também houve significância ( $p=0.0237)$, de acordo com o Gráfico 2 .

Gráfico 2 - Painel gráfico de linha de dados do tempo de garrote pelo tempo de cirurgia por tipo de procedimento (tempo em minutos)

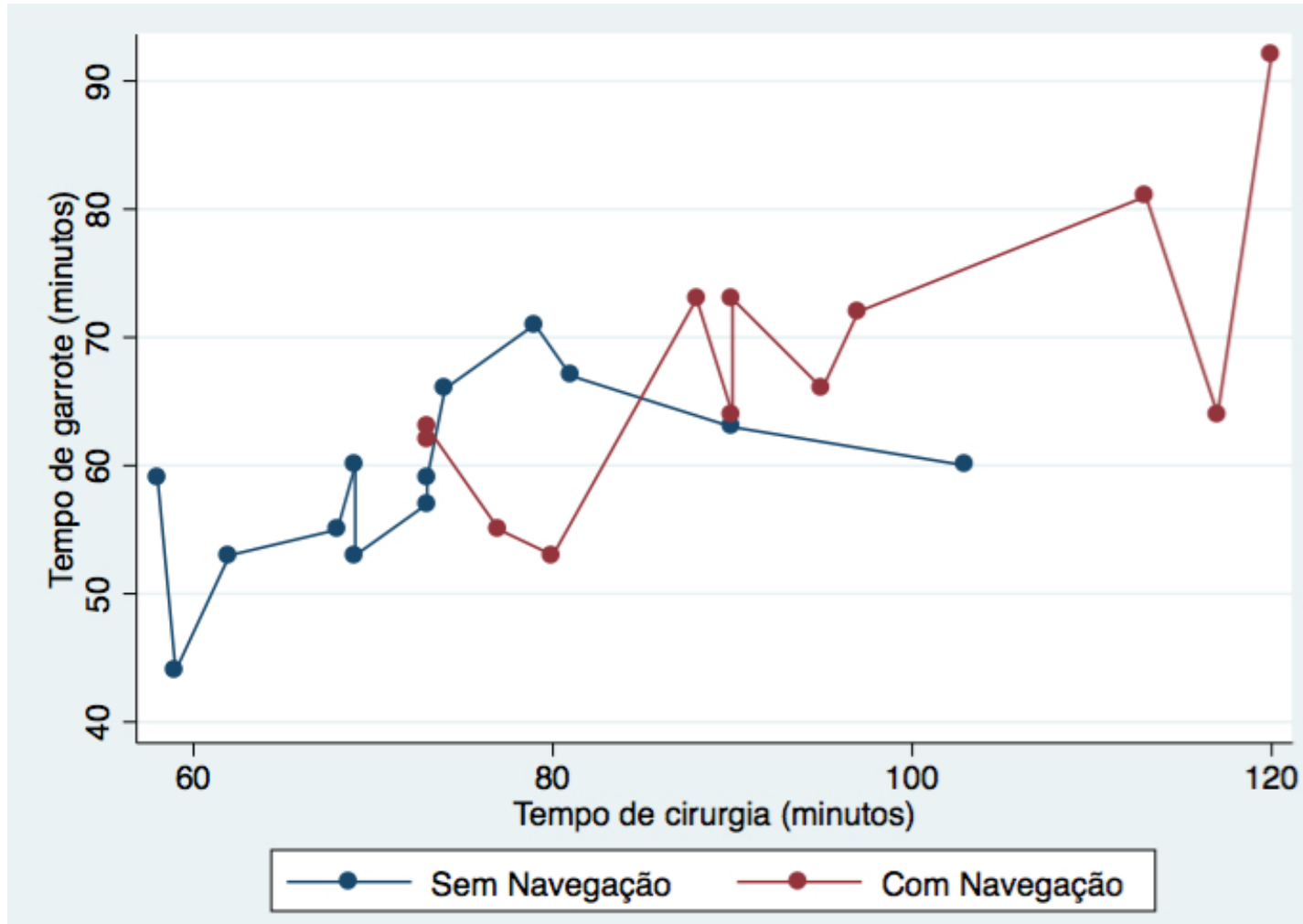

Com relação ao alinhamento mecânico, no pré-operatório a média absoluta foi de 13,84 para cirurgia convencional e 14,4 para os pacientes submetidos a técnica com navegação $(p=0.7432$; IC95\% 12,8 -15,4). 
Tabela 2 - Comparação do alinhamento pré-operatório e pós-operatório entre os grupos

\begin{tabular}{lcccccc}
\hline & $\begin{array}{c}\text { CONVENCIONAL } \\
(\mathrm{n}=13)\end{array}$ & \multicolumn{4}{c}{$\begin{array}{c}\text { GUIADA POR } \\
\text { NAVEGAÇÃO } \\
(\mathrm{n}=12)\end{array}$} \\
& Média & DP & Média & DP & IC 95\% & $P$ \\
\hline $\begin{array}{l}\text { Alinhamento } \\
\text { (Pré-Operatório) }\end{array}$ & 13,84 & 3,44 & 14,4 & 2,97 & $12,8-15,4$ & 0.7432 \\
$\begin{array}{l}\text { Alinhamento } \\
\text { (Pós-Operatório) }\end{array}$ & 1,08 & 1,5 & 0,25 & 1,14 & $0,08-1,24$ & 0.1316 \\
\hline
\end{tabular}

Obtivemos os seguintes resultados de alinhamento mecânico final.

Tabela 3 - Média e desvio padrão do alinhamento mecânico pósoperatório: técnica convencional e navegação

\begin{tabular}{ccccc}
\hline & \multicolumn{2}{c}{ TÉCNICA CONVENCIONAL } & \multicolumn{2}{c}{ COM USO DE NAVEGAÇÃO } \\
Alinhamento & $\begin{array}{c}\text { Alinhamento } \\
\text { Alinhamento } \\
\text { Pós }\end{array}$ & $\begin{array}{c}\text { Plinhamento } \\
\text { Prés }\end{array}$ \\
\hline 1 & 11 & 1 & 13 & 2 \\
2 & 15 & 0 & 10 & 3 \\
3 & 11 & 2 & 9 & 0 \\
4 & 17 & -1 & 16 & -1 \\
5 & 21 & -2 & 12 & 1 \\
6 & 16.5 & 1 & 9 & 2 \\
7 & 15 & 1 & 13 & 2 \\
8 & 12 & 1 & 18 & 3 \\
9 & 13 & 0 & 13 & -1 \\
10 & 16 & 0 & 14 & -1 \\
11 & 11.5 & 1 & 16 & 2 \\
12 & 14 & -1 & 20 & 1 \\
13 & & & 17 & \\
Média & 14,50 & 0,25 & 13,85 & 1,08 \\
Desvio Padrão & 3,06 & 1,14 & 3,44 & 1,51 \\
\hline
\end{tabular}


O alinhamento final mecânico variou de -2 a 3 (gráfico box plot) e, não foi diferente entre as técnicas aplicadas ( $p=0.1316$; IC95\% 0,08-1,24).

Gráfico 3- Box plot do alinhamento pré e pós-operatório por tipo de técnica utilizada

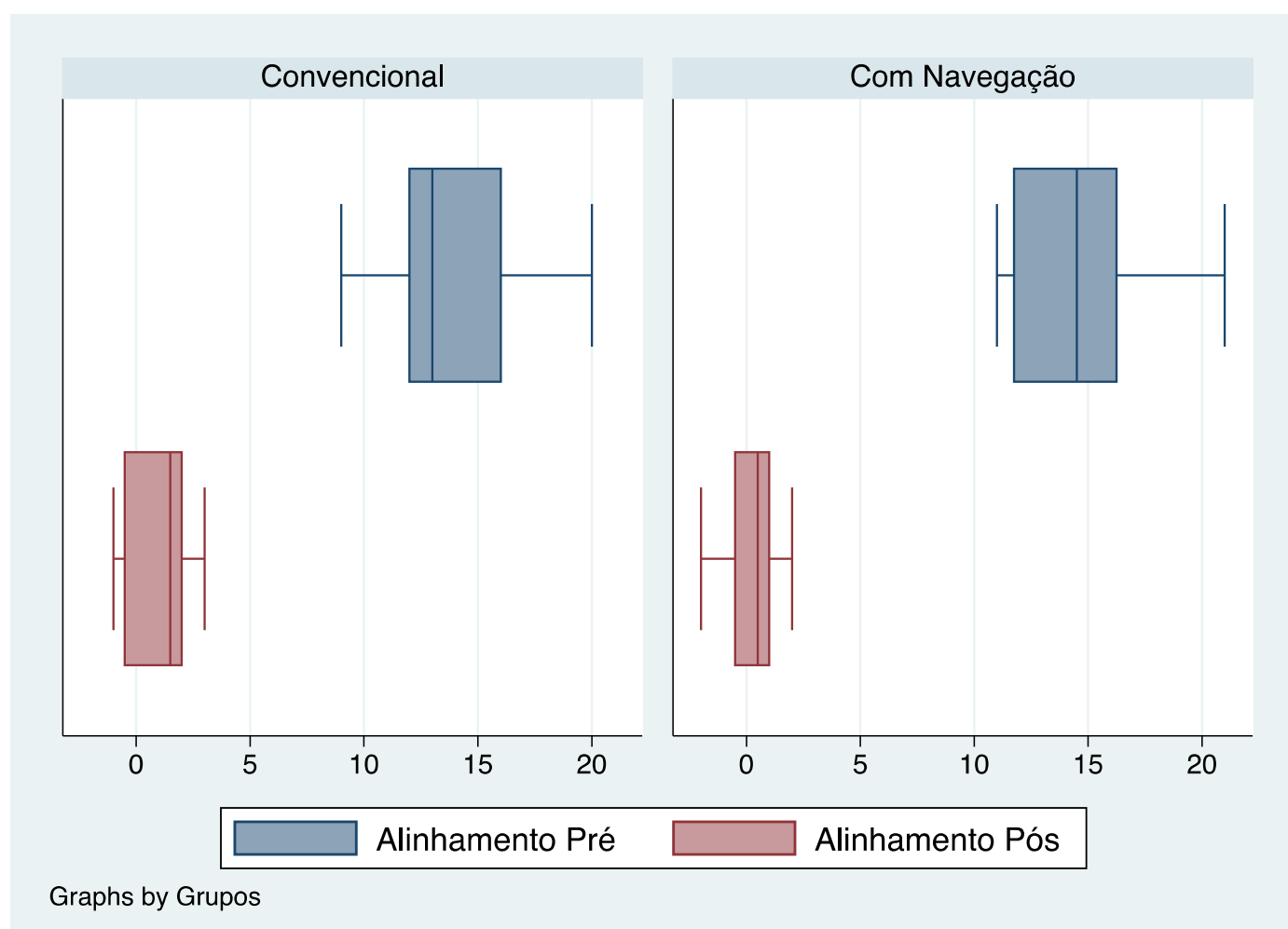

Para verificar a correlação entre o alinhamento mecânico inicial e o resultado no pós-operatório, foi realizada a Correlação de Spearman. Desta forma, verificamos uma forte correlação $(\rho=-0,68)$ para o grupo com uso de navegação ( $p=0.0143)$, sugerindo que para qualquer valor de alinhamento inicial, o resultado (o alinhamento final) será o melhor possível (próximo de zero). Não se observou o mesmo para a técnica convencional cujo 
coeficiente de correlação, foi de $\rho=-0.07(p=0.8310)$, ou seja, correlação baixa.

Gráfico 4- A. Scatter plot com linha de correlação entre alinhamento inicial e final para o grupo com uso de navegação. B. Scatter plot com linha de correlação entre alinhamento inicial e final para o grupo com uso de técnica convencional
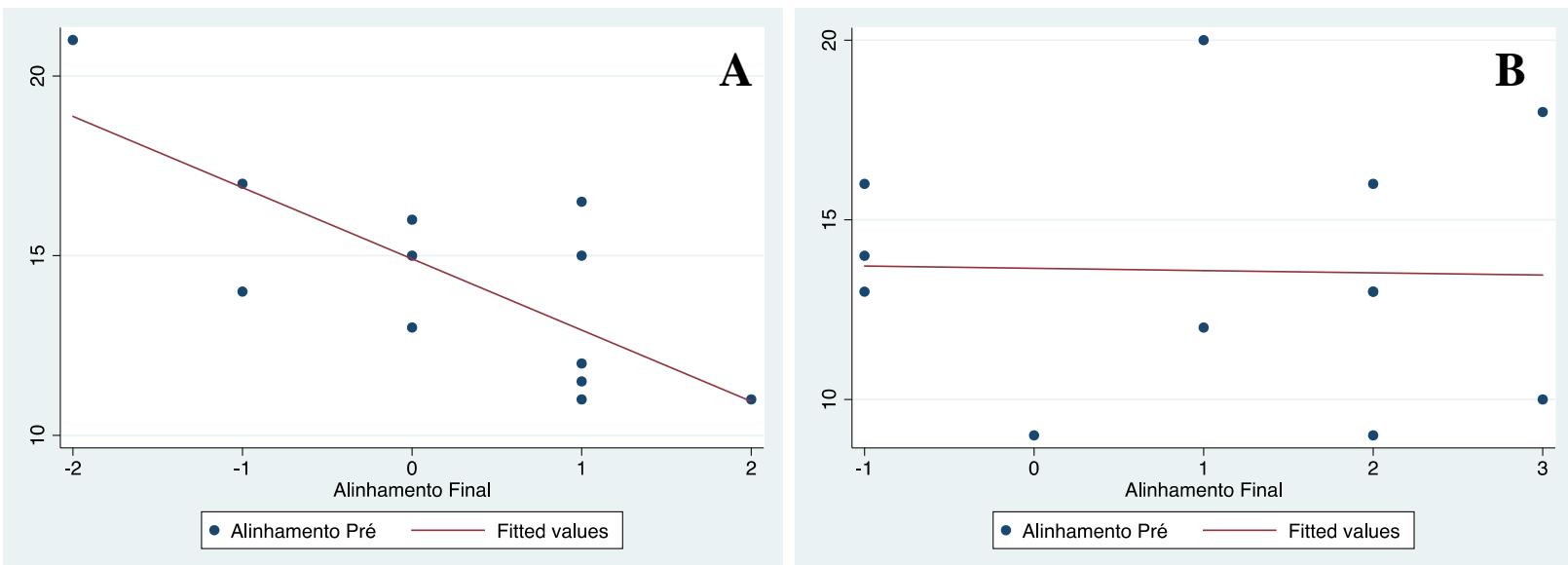

Dividimos o resultado do alinhamento pós-operatório em 3 grupos, conforme a tabela abaixo. Estes considerados "outliers" os valores fora da margem de erro de $>=3^{\circ}$ de alinhamento final. 
Tabela 4 - Valores fora da margem de erro por grupo

\begin{tabular}{lccc}
\hline & $\begin{array}{c}\text { Convencional } \\
(\mathrm{n}=13)\end{array}$ & $\begin{array}{c}\text { Guiada por } \\
\text { navegação } \\
(\mathrm{n}=12)\end{array}$ & $p$ \\
\hline $\begin{array}{l}\text { I.Fora da margem de erro de } \pm 3 \\
\text { (n/\%) }\end{array}$ & $02(16,7)$ & $0(0)$ & 0.239 \\
$\begin{array}{l}\text { II.Fora da margem de erro de } \pm 2 \\
\text { (n/\%) }\end{array}$ & $04(33,3)$ & $02(16,7)$ & 0.097 \\
$\begin{array}{l}\text { III.Fora da margem de erro de } \pm \\
1(\mathrm{n} / \%)\end{array}$ & $06(50)$ & $10(83,3)$ & 0.097 \\
\hline
\end{tabular}

No grupo convencional, $17 \%$ dos procedimentos estavam fora da margem de erro, porém não houve casos de outliers no grupo navegado e, ao comparar diferença estatística não obtivemos significância (Fisher's exact $=0.239)$.

Por outro lado, $83 \%$ dos procedimentos realizados com a técnica convencional estavam dentro da margem e $100 \%$ daqueles realizados com uso da navegação.

Ao reduzir ainda mais a margem de erro para maior de $\pm 2^{\circ}$ de alinhamento mecânico final, temos $50 \%$ de casos fora desta margem para o grupo convencional, versus $16,7 \%$ para o grupo navegado, sendo o valor do teste exato de Fisher $p=0.097$. 
Os valores sugerem uma proporção alta de $50 \%$ de erro para a técnica convencional, de acordo com os parâmetros de $\pm 2^{\circ}$ de alinhamento mecânico, porém uma amostra maior pode revelar uma possível diferença entre os grupos.

A escala KSS (Knee Society Scoring System) foi aplicada para todos os pacientes no pré e pós-operatório quanto ao nível de atividade, dor e instabilidade.

Tabela 5- Comparação do escore KSS entre os grupos. ${ }^{(*)}$ Knee society score system

\begin{tabular}{|c|c|c|c|c|c|c|}
\hline & \multicolumn{6}{|c|}{$\begin{array}{c}\text { GUIADA POR } \\
\text { NAVEGAÇÃO } \\
(\mathrm{N}=12)\end{array}$} \\
\hline & Média & DP & Média & DP & IC 95\% & $p$ \\
\hline $\begin{array}{l}\mathrm{KSS}^{(*)} \text { (Pré- } \\
\text { Operatório) }\end{array}$ & 56,25 & 12,27 & 55 & 10,87 & $50,8-60,4$ & 0.7476 \\
\hline $\begin{array}{l}\text { KSS }^{(*)} \text { (Pós- } \\
\text { Operatório) }\end{array}$ & 84,58 & 8,64 & 82,08 & 7,82 & $79,8-86,8$ & 0.4638 \\
\hline
\end{tabular}

No pré-operatório, a escala média do grupo submetido à técnica convencional foi de $56,25 \%$, semelhante ao outro grupo, com média de $55 \%$ $(p=0.7476)$. No pós-operatório, houve melhora do nível de atividade, dor e instabilidade, porém não foi diferente entre os grupos estudados. 
Gráfico 5- Box plot do escore KSS do pré e pós-operatório entre os tipos de técnicas utilizadas

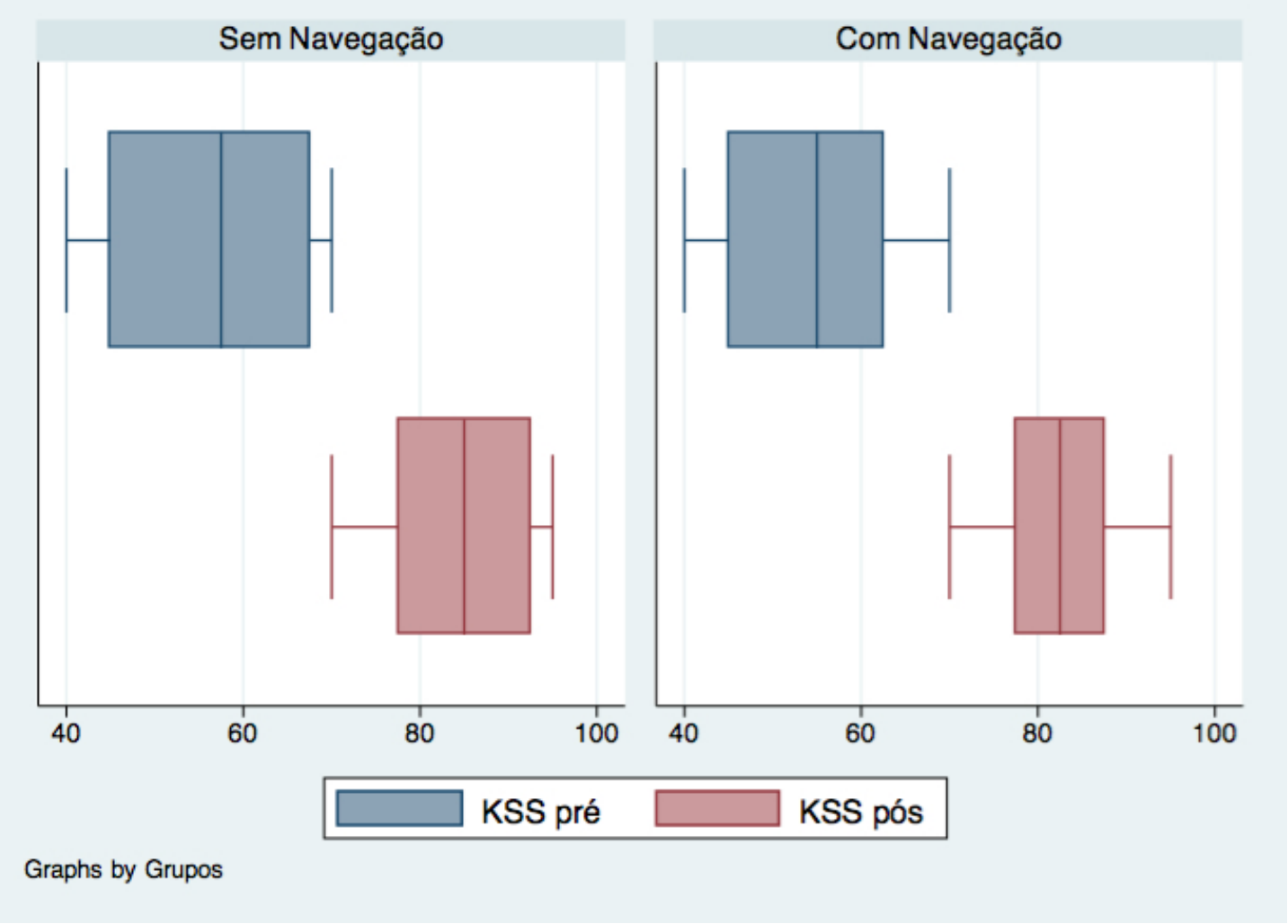

A média de alinhamento pós-operatório não foi diferente estatisticamente quanto ao tipo de técnica utilizada $(p=0.1316)$ e, também não houve diferença no KSS pós-operatório $(p=0.4638)$ dos pacientes submetidos à osteotomia. 
6. Discussão 


\section{DISCUSSÃO}

A importância do alinhamento mecânico após as cirúrgicas ortopédicas é citada como um fator da grande importância para o sucesso da técnica empregada seja uma artroplastia total de joelho, uma osteossíntese de fêmur, tíbia ou tornozelo. Os desvios no eixo coronal são causas de insucesso e queixas frequentes dos pacientes (Kendoff et al., 2010).

As osteotomias são reconhecidamente cirurgias de difícil execução. Pequenos erros na indicação, execução e ou reabilitação podem ocasionar uma lista enorme de complicações e um resultado insatisfatório. Entre estas complicações podemos citar: fratura intra-articular, soltura ou quebra do material de síntese, quebra da cortical óssea, instabilidade articular, infecção, pseudoartrose, trombose, parestesia, super ou sub-correção angular da deformidade, redução do ADM, atitude em flexo (Jackson \& Warkentine, 2007). Quanto mais precocemente estas complicações acontecem, maior a taxa de conversão da osteotomia em artroplastia total.

Estes fatores somados a evolução da longevidade e melhoria da técnica cirúrgica da artroplastia total de joelho induziram a redução no número de osteotomias realizadas nos EUA e Canadá (Wriht et al., 1995).

Em 2007, Puddu et al. publicam uma técnica inovadora, advogando o uso de uma cunha de adição lateral nos fêmures valgos. E ainda, 
preconizam o uso de uma placa - calço, segundo ele, cada milímetro de calço da placa representaria um grau de correção angular no eixo mecânico.

A introdução desta técnica, de certa maneira, facilitou o procedimento cirúrgico, com um calço pré-determinado entre 7 e 15 mm, a correção do eixo mecânico estaria dentro de um padrão. Assim muitos ortopedistas retomaram a técnica de osteotomia, e a indicação destas aumentou significativamente.

Anteriormente a técnica de Puddu havia poucos parâmetros intraoperatórios de correção das deformidades. Valia a experiência do cirurgião que muitas vezes lançava mão de algumas "artimanhas" como: usar uma haste longa e a radioscopia intra-operatória como parâmetro de eixo mecânico, ou até mesmo o fio do eletrocautério, referido por alguns autores como "método do cabo" (Krettek et. al., 1998).

Com isso a necessidade de melhorar os resultados e a longevidade das osteotomias tornou-se essencial desenvolver meios e técnicas de controle intra-operatório do alinhamento do membro.

A introdução de novos e desconhecidos instrumentais na prática clínica, no ambiente hospitalar e ainda mais na sala cirúrgica, enfrenta inúmeras reações: desde a descrença ao medo de substituição da mão de obra humana (Taylor et al., 1995). 
O maior tempo cirúrgico, o maior de tempo garroteamento e a introdução de novos e desconhecidos instrumentais constituem uma grande curva de aprendizagem a ser vencida pelos médicos ortopedistas.

O grande objetivo da navegação é auxiliar o cirurgião a obter posicionamento preciso com os componentes protéticos e alinhamento mecânico adequado no caso das osteotomias, ou seja, cirurgias mais precisas com menos erros e resultados mais confiáveis (Siston et al., 2007).

A união de uma técnica cirúrgica consagrada com esta nova ferramenta encontra no dia- a- dia do ortopedista alguns obstáculos: maior tempo cirúrgico, maior de tempo garroteamento do membro e introdução de novos e desconhecidos instrumentais constituem uma grande curva de aprendizagem a ser vencida. Há certamente um grau de rejeição inicial que qualquer técnica nova enfrenta principalmente dos cirurgiões satisfeitos com seus resultados e técnica operatória (Taylor et al., 1999).

Nossos resultados vêm de acordo com a literatura (Hankemeier et al., 2006; Jackson et al., 2007) quanto ao maior tempo de cirurgia e do tempo de garrote, ambos estatisticamente significantes. Porém, estes tempos mais elevados não prejudicaram o resultado final e tão pouco causaram qualquer complicação clínica. 
Na literatura não há um grande número de trabalhos sobre osteotomia femoral distal varizante. E é menor ainda a quantidade de trabalhos sobre osteotomia femoral navegada. Nosso estudo prospectivo e randomizado procura contribuir para o desenvolvimento do tema ao avaliar a reprodutibilidade da técnica e os resultados clínicos e radiográficos precoces.

Ao avaliar o eixo mecânico através de radiografias estamos sujeitos a algumas imprecisões: de mensuração: a avaliação do centro do tornozelo, centro de rotação da cabeça femoral e centro de joelho; e de técnica: rotação interna ou externa dos membros inferiores na posição de decúbito dorsal. Porém, este é o método mais utilizado na prática clínica.

O número de pacientes com osteoartrose unicompartimental em valgo I não é grande, encontramos na literatura vários trabalhos com a casuística semelhante: Edgerton et al.,1993 com 23 pacientes; Finkelstein et al.,1996 com 20 pacientes; Stahelin et al., 2000 com 19 pacientes, Das et al., 2008 com 12 pacientes. E também outros como: Wang et al., 2006 com 30 pacientes e Backstein et al., 2007 com 38 pacientes.

Outro fator relevante em nosso meio é o entendimento perfeito sobre a reabilitação e a adesão do paciente a ela. Durante este estudo, tivemos uma soltura de placa no $23^{\circ}$ dia pós-operatório, o paciente não obedeceu às orientações de não pisar e caminhava sem o auxílio de muletas. Este 
paciente recusou-se a reoperar, apresentou uma consolidação caótica, porém estável e apresentava um arco de movimento de 0-85 grau, foi excluído do estudo. Todos estes fatores justificam a nossa casuística.

Não encontramos diferença significativa quanto ao alinhamento pré e pós entre os grupos convencional e navegação, porém houve uma forte correlação no grupo com navegação, que produz resultados mais homogêneos e menos "outliers". Quando dividimos os resultados do alinhamento em grupos, a margem de erro para maior de $\pm 2^{0}$ de alinhamento mecânico final obtivemos $50 \%$ de casos fora desta margem para o grupo convencional, versus $16,7 \%$ para o grupo navegado. Esta tendência observada no grupo navegado de produzir resultados mais próximos de eixo mecânico ideal, ou seja, zero é uma vantagem do método sobre o convencional (Reising et al., 2013).

Com o objetivo de identificar quantos indivíduos seriam necessários em cada grupo, aplicamos o cálculo amostral, utilizando nossos valores de média e desvio padrão de alinhamento final como referência com alfa unicaudal de 0.05 e beta (poder de 0.80 ). No total, 64 pacientes, sendo 32 em cada grupo poderiam identificar diferença estatística entre os grupos.

Neste estudo, utilizamos o sistema de navegação utilizado: "StrykerHowmedica Navigation Software", este mensura e indica as variações do eixo mecânico no plano coronal durante o procedimento cirúrgico, após ter 
sido corretamente alimentado com referências anatômicas pelo cirurgião. Neste sistema não há indicação do posicionamento do fêmur distal no plano sagital, o que é uma limitação do nosso estudo. Além disso, alguns outros de problemas/erros podem ocorrer: de informação imprecisa dos pontos anatômicos, solturas dos pinos de Schanz, manutenção inadequada do navegador.

Em contra partida, é inegável a aplicação da navegação na ortopedia, seja nas artroplastias ou nas osteotomias, vários autores têm demonstrado paulatinamente que quantidade de informação "nova" obtida em tempo real na sala cirúrgica, pode facilitar o procedimento do cirurgião, diminuir o tempo de planejamento pré-operatório e minimizar mau alinhamento nos casos de grande deformidade (Saragaglia et al., 2010).

Certamente, há um longo caminho a percorrer no desenvolvimento dos sistemas de navegação. Informações como: altura da patela, alinhamento superfície articular, rotação do membro inferior, rotação e ou flexão do fêmur distal, e de balanceamento ligamentar seriam avanços importantes nas próximas gerações de navegadores, como também aparatos menores, mais leves, mais fáceis e mais rápidos de manusear.

Ainda, advogo que no futuro haja gerações de navegadores cirúrgicos "universais" que sirvam para qualquer síntese (placas, parafusos) e para qualquer prótese. E não sejam "exclusividades" de uma marca e de um 
fornecedor. E estejam presentes em qualquer centro cirúrgico, como uma simples ferramenta.

Avaliar estes resultados clínicos e radiográficos em longo prazo, a sua taxa de conversão para artroplastia total e compará-los com os resultados de uma nova geração de navegadores são desafios e tema de grande interesse para novos estudos. 
7. Conclusões 


\section{CONCLUSÕES}

1. Não encontramos diferença no alinhamento final das osteotomias femorais varizantes com ou sem navegação.

2. Não encontramos diferença no resultado clínico das osteotomias femorais com e sem navegação.

3. O tempo de cirurgia e tempo de garrote foram maiores no grupo com navegação. 


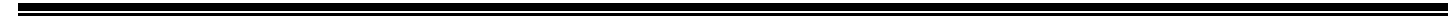

8. Anexos 
ANEXO A

\begin{tabular}{|c|c|c|c|c|c|c|c|c|c|}
\hline & \multirow{2}{*}{ Nota } & \multicolumn{4}{|c|}{ Esquerdo } & \multicolumn{4}{|c|}{ Direito } \\
\hline & & Pré & Inès & 6 nês & 1 ano & Pre & 3nês & 6 nès & 1 ano \\
\hline Dor-Nenhuna & 50 & & & & & & & & \\
\hline Leve ou ocrsional & 45 & & & & & & & & \\
\hline Apenas en escrida & 40 & & & & & & & & \\
\hline Ao caninhar e en eacada & 30 & & & & & & & & \\
\hline Moderada ocisional & 20 & & & & & & & & \\
\hline Conf nua & 10 & & & & & & & & \\
\hline Forte & 0 & & & & & & & & \\
\hline Arplinude de novinento (5' -1 ponto) & 25 & & & & & & & & \\
\hline \multicolumn{2}{|l|}{ Estabiidade (nov. max en qualquer poesiça) } & & & & & & & & \\
\hline$A / P<5$ & 10 & & & & & & & & \\
\hline $5-10 \mathrm{~mm}$ & 5 & & & & & & & & \\
\hline $10 \mathrm{~mm}$ & 0 & & & & & & & & \\
\hline$M L<5^{\prime}$ & 15 & & & & & & & & \\
\hline $6-9^{4}$ & 10 & & & & & & & & \\
\hline $10-14^{4}$ & 5 & & & & & & & & \\
\hline $15^{\prime}$ & 0 & & & & & & & & \\
\hline \multicolumn{10}{|l|}{ Total } \\
\hline \multicolumn{10}{|l|}{ Deduọ́ es (nenos) } \\
\hline \multicolumn{2}{|l|}{ Contratura en flexio } & & & & & & & & \\
\hline Nenhun & 0 & & & & & & & & \\
\hline $5-10^{\prime}$ & 2 & & & & & & & & \\
\hline $10-15^{1}$ & 5 & & & & & & & & \\
\hline $16-20^{4}$ & 10 & & & & & & & & \\
\hline$>20^{4}$ & 15 & & & & & & & & \\
\hline \multicolumn{10}{|l|}{ Défict de extensílo } \\
\hline Nenhun & 0 & & & & & & & & \\
\hline$<10^{4}$ & 5 & & & & & & & & \\
\hline $10-20^{4}$ & 10 & & & & & & & & \\
\hline$>20^{4}$ & 15 & & & & & & & & \\
\hline \multicolumn{10}{|l|}{ Alinhanento } \\
\hline $5-10^{\prime}$ (nenhun) & 0 & & & & & & & & \\
\hline \multicolumn{10}{|l|}{$0-4^{4}$ (3 pontos por grau) } \\
\hline \multicolumn{10}{|l|}{$11-15^{\prime}$ (3 pontoe por graus) } \\
\hline Outros & 20 & & & & & & & & \\
\hline \multicolumn{10}{|l|}{ Total de ded uç̄es } \\
\hline \multirow{2}{*}{\multicolumn{10}{|c|}{ 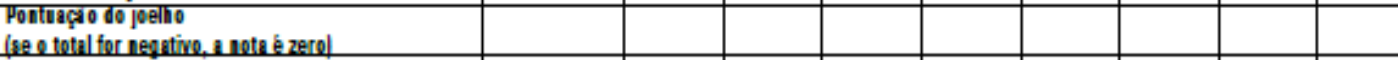 }} \\
\hline & \multicolumn{9}{|c|}{ Funder o } \\
\hline Cuninhar: Sen linites & 50 & & & & & & & & \\
\hline$>800$ netros & 40 & & & & & & & & \\
\hline 400 a 800 metros & 30 & & & & & & & & \\
\hline$<400$ netros & 20 & & & & & & & & \\
\hline Anda dentro de casa & 10 & & & & & & & & \\
\hline Nío anda & 0 & & & & & & & & \\
\hline Escada: Nomal para subir e descer & 50 & & & & & & & & \\
\hline Nomal para subir, usa corrinío para descer & 40 & & & & & & & & \\
\hline Uso de corinío para subir e descar & 30 & & & & & & & & \\
\hline Cominí p para subir, nfo coneague descer & 15 & & & & & & & & \\
\hline Nío consegue aubir nen deacer & 0 & & & & & & & & \\
\hline \multicolumn{10}{|l|}{ Total } \\
\hline \multicolumn{9}{|l|}{ Deduḉ es (nenos) } & \\
\hline Bengala & 5 & & & & & & & & \\
\hline Durs bengalas & 10 & & & & & & & & \\
\hline Muleta / Andador & 20 & & & & & & & & \\
\hline Total de deduçóes & & & & & & & & & \\
\hline Nota da funçĩo & & & & & & & & & \\
\hline
\end{tabular}




\section{ANEXO B}

HOSPITAL DAS CLÍNICAS DA FACULDADE DE MEDICINA DA UNIVERSIDADE DE SÃO PAULO-HCFMUSP

MODELO DE TERMO DE CONSENTIMENTO LIVRE E ESCLARECIDO

\section{DADOS DE IDENTIFICAÇÃO DO SUJEITO DA PESQUISA OU RESPONSÁVEL LEGAL \\ 1. NOME:}

DOCUMENTO DE IDENTIDADE N ${ }^{\circ}$ :

SEXO : .M $\square \quad \mathrm{F}$

DATA NASCIMENTO:

ENDEREÇO

$\mathrm{N}^{\mathrm{o}}$

APTO:

BAIRRO:

CIDADE

CEP:

TELEFONE: DDD

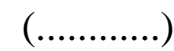

2.RESPONSÁVEL

LEGAL

NATUREZA (grau de parentesco, tutor, curador etc.)

DOCUMENTO DE IDENTIDADE : .SEXO: $\mathrm{M} \square \mathrm{F} \square$

DATA NASCIMENTO.: .....................

ENDEREÇO:

$\mathrm{N}^{\mathrm{o}}$ APTO:

CIDADE:

BAIRRO:

TELEFONE:

DDD

CEP:

............

DADOS SOBRE A PESQUISA

1. TÍTULO DO PROTOCOLO DE PESQUISA: Osteotomia femoral varizante orientada por navegação e assistida por artroscopia. Descrição de técnica cirúrgica e resultados

2. PESQUISADOR : DR. ROBERTO F DA MOTA E ALBUQUERQUE

CARGO/FUNÇÃO: medico assistente INSCRIÇÃO CONSELHO REGIONAL Nº 49864 
UNIDADE DO HCFMUSP: INSTITUTO DE ORTOPEDIA E TRAUMATOLOGIA

3. AVALIAÇÃO DO RISCO DA PESQUISA:

RISCO MÍNIMO X RISCO MÉDIO

RISCO BAIXO $\quad$ RISCO MAIOR

4. DURAÇÃO DA PESQUISA: (02) DOIS ANOS

\section{HOSPITAL DAS CLÍNICAS DA FACULDADE DE MEDICINA DA UNIVERSIDADE DE SÃO PAULO-HCFMUSP}

1. Este estudo cujo tema é: Estudo comparativo da osteotomia femoral varizante orientada por navegação. Descrição de técnica cirúrgica e resultados. Tem por objetivo avaliar os resultados uma nova técnica cirúrgica de um procedimento já estabelecido, e reconhecido como valioso no tratamento da osteoartrose: A osteotomia do fêmur (osso da coxa).

2. A osteotomia consiste em realizar um corte cirúrgico no osso da coxa e sua fixá-la com uma placa e parafusos. Assim ela terá outro alinhamento (posição). Melhorando as queixas associadas aos desvios e a artrose de joelho. Neste procedimento utilizaremos um computador (navegador) para nos auxiliar durante o procedimento cirúrgico, realizando cortes ósseos mais precisos.

3. Você foi selecionado para este procediemnto porque sua doença (osteoartrose) não teve bons resultados como tratamento conservador (fisioterapia, analgésicos, etc)

4. Durante este estudo, você será submetido antes e após o procedimento cirúrgico a: avaliações radiográficas (raios-X) de seus membros inferiores: coxas, joelhos e perna; será submetido a um questionários (perguntas) sobre as suas queixas em relação a dor, instabilidade, desvios, dos seus membros inferiores, principalmente os joelhos.

5. Antes de qualquer procedimento cirúrgico você será submetido a exames préoperatórios: de sangue, eletrocardiograma e rx de tórax, somente será liberado se estes estiverem bons. Se alguma doença como diabetes, hipertensão forem diagnosticadas você será encaminhado ao ambulatório especifico para tratamento e acompanhamento.

6. Durante o procedimento cirúrgico, você será anestesiado, sedado e será submetido a todos os cuidados rotineiros de um paciente cirúrgico.

7. Logo após o procedimento cirúrgico (cirurgia): você será medicado, imobilizado e orientado, mesmo assim pode ocorrer: dor local, edema, inchaço, 
sensação de peso e anestesia (formigamento), calor que devem ceder com o passar dos dias.

8. Após este procedimento você terá um novo alinhamento dos membros inferiores , o que proporciona o alívio progressivo de sua queixas relacionados a osteoartrose e a este desvio.

9. Garantia de acesso: em qualquer etapa do estudo, você terá acesso aos profissionais responsáveis pela pesquisa para esclarecimento de eventuais dúvidas. O principal investigador é o DR. ROBERTO F DA MOTA E ALBUQUERQUE que pode ser encontrado no endereço Instituto de Ortopedia e Traumatologia do Hospital das Clinicas da FMUSP. Rua Dr. Ovídio Pires de Campos, 333 Telefone(s) 30696416. Se você tiver alguma consideração ou dúvida sobre a ética da pesquisa, entre em contato com o Comitê de Ética em Pesquisa (CEP) - Rua Ovídio Pires de Campos, 225 - $5^{\circ}$ andar - tel: 3069-6442 ramais 16, 17, 18 ou 20, FAX: 3069-6442 ramal 26 - Email: cappesq@hcnet.usp.br

10. É garantida a liberdade da retirada de consentimento a qualquer momento e deixar de participar do estudo, sem qualquer prejuízo à continuidade de seu tratamento na Instituição.

11. Direito de confidencialidade - As informações obtidas serão analisadas em conjunto com outros pacientes, não sendo divulgado a identificação de nenhum paciente.

12. Direito de ser mantido atualizado sobre os resultados parciais das pesquisas, quando em estudos abertos, ou de resultados que sejam do conhecimento dos pesquisadores.

13. Despesas e compensações: não há despesas pessoais para o participante em qualquer fase do estudo, incluindo exames e consultas. Também não há compensação financeira relacionada à sua participação. Se existir qualquer despesa adicional, ela será absorvida pelo orçamento da pesquisa.

14. Compromisso do pesquisador de utilizar os dados e o material coletado somente para esta pesquisa.

Acredito ter sido suficientemente informado a respeito das informações que li ou que foram lidas para mim, descrevendo o estudo. "Estudo comparativo da osteotomia femoral varizante em cunha de abertura pelo método convencional x navegação" Eu discuti com o DR. ROBERTO F DA MOTA E ALBUQUERQUE sobre a minha decisão em participar nesse estudo. Ficaram claros para mim quais são os propósitos do estudo, os procedimentos a serem realizados, seus desconfortos e riscos, as garantias de confidencialidade e de esclarecimentos permanentes. Ficou claro 
também que minha participação é isenta de despesas e que tenho garantia do acesso a tratamento hospitalar quando necessário.

Concordo voluntariamente em participar deste estudo e poderei retirar o meu consentimento a qualquer momento, antes ou durante o mesmo, sem penalidades ou prejuízo ou perda de qualquer benefício que eu possa ter adquirido, ou no meu atendimento neste Serviço.

Assinatura do paciente/representante legal Data

$1 /$

Assinatura da testemunha

Data

11

para casos de pacientes menores de 18 anos, analfabetos, semi-analfabetos ou portadores de deficiência auditiva ou visual.

(Somente para o responsável do projeto)

Declaro que obtive de forma apropriada e voluntária o Consentimento Livre e Esclarecido deste paciente ou representante legal para a participação neste estudo.

DR. ROBERTO F DA MOTA E ALBUQUERQUE

Assinatura do responsável pelo estudo Data $1 / 1$ 
9. Referências 


\section{REFERÊNCIAS}

Aglietti P, Menchetti PP. Distal femoral varus osteotomy in the valgus osteoarthritic knee. Am J Knee Surg. 2000;13(2):89-95.

Akamatsu Y, Koshino T, Saito T, Wada J. Changes in osteoclerosis of the ostheoarthritic knee after high tibial osteotomy. Clin Orthop Relat Res. 1997;(334):207-14 .

Albuquerque R, Angelini F, Pecora J, Amatuzzi M, Sasaki S. Artroplastia total do joelho assistida por computador. Acta Ortop Bras. 2006;14(4):199-202.

Amiot LP, Poulin F. Computed tomography-based navigation for hip, knee, and spine surgery. Clin Orthop Relat Res. 2004;(421):77-86.

Andrade MAP, Gomes DCFF, Portugal AL, Silva GMA. Osteotomia femoral distal de varização para osteoartrose no joelho valgo: seguimento em longo prazo. Rev Bras Ortop. 2009;44(4):346-50

Backstein D, Morag G, Hanna S, Safir O, Gross A. Long-term follow-up of distal femoral varus osteotomy of the knee. J Arthroplasty. 2007;22(4 Suppl 1):2-6. 
Berman AT, Bosacco SJ, Kirshner S, Avolio A Jr. Factors influencing longterm results in high tibial osteotomy. Clin Orthop Relat Res. 1991;(272):1928.

CDC - Centers for Diseases Control and Prevention. Osteoarthritis. Atlanta: CDC; $2013 . \quad$ Disponível em: http://www.cdc.gov/arthritis/basics/osteoarthritis.htm.

Chao EY, Sim FH. Computer-aided preoperative planning in knee osteotomy. lowa Orthop J. 1995;15:4-18.

Coventry MB. Osteotomy about knee for degenerative and rheumatoid arthritis. J Bone Joint Surg Am. 1973;55(1):23-48.

Coventry MB. Proximal tibial varus osteotomy for osteoarthritis of the lateral compartment of the knee. J Bone Joint Surg Am. 1987;69(1):32-8.

Coventry MB. Upper tibial osteotomy for osteoarthritis. J Bone Joint Surg Am. 1985;67(7):1136-40.

Das DHPW , Sijbesma T, Hoekstra HJ, van Leeuwen WM. Distal femoral opening-wedge osteotomy for lateral compartment osteoarthritis of the knee. Open Access Surgery. 2008;1:25-9. 
DiGioia AM 3rd, Jaramaz B, Blackwell M, Simon DA, Morgan F, Moody JE, Nikou C, Colgan BD, Aston CA, Labarca RS, Kischell E, Kanade T. The Otto Aufranc Award. Image guided navigation system to measure intraoperatively acetabular implant alignment. Clin Orthop Relat Res. 1998;(355):8-22.

Dillon CF, Rasch EK, Gu Q, Hirsch R. Prevalence of knee osteoarthritis in the United States: arthritis data from the Third National Health and Nutrition Examination Survey 1991-94. J Rheumatol. 2006;33(11):2271-9.

Edgerton BC, Mariani EM, Morrey BF. Distal femoral varus osteotomy for painful genu valgum. A five-to-11-year follow-up study. Clin Orthop Relat Res. 1993;(288):263-9.

Ewald FC. The Knee Society total knee arthroplasty roentgenographic evaluation and scoring system. Clin Orthop Relat Res. 1989;(248):9-12.

Finkelstein JA, Gross AE, Davis A. Varus Osteotomy of the distal part of the femur. A survivorship analysis. J Bone Joint Surg Am. 1996;78(9):1348-52.

Franco V, Cerullo G, Cipolla M, Gianni E, Puddu G. Open wedge high tibial osteotomy. Tech Knee Surg. 2002;1:43-53. 
Hankemeier S, Hufner T, Wang G, Kendoff D, Zeichen J, Zheng G, Krettek C. Naviated open-wedge high tibial osteotomy: advantages and disadavantages compared to the conventional technique in a cadaver study. Knee Surg Sports Traumatol Arthrosc. 2006;14(10):917-21.

Hankemeier S, Mommsen P, Krettek C, Jagodzinski M, Brand J, Meyer C, Meller R. Accuracy of high tibial osteotomy: comparison between open- and closed-wedge technique. Knee Surg Sports Traumatol Arthrosc. 2010;18(10):1328-33.

Harding ML. A fresh appraisal of tibial osteotomy for osteoarthritis of the knee. Clin Orthop Relat Res. 1976;(114):223-34.

Healy WL, Anglen JO, Wasilewski SA, Krackow KA. Distal fermoral varus osteotomy. J Bone Joint Surg Am. 1988;70(1):102-9.

Insall JN, Joseph DM, Msika C. High tibial osteotomy for varus gonarthrosis. A long-term follow-up study. J Bone Joint Surg Am. 1984;66(7):1040-8.

lorio R, Pagnottelli M, Vadalà A, Giannetti S, Di Sette P, Papandrea P, Conteduca F, Ferretti A. Open-wedge high tibial osteotomy: comparison between manual and computer-assisted techniques. Knee Surg Sports Traumatol Arthrosc. 2013;21(1):113-9. 
Jackson DW, Warkentine B. Technical aspects of computer-assisted opening wedge high tibial osteotomy. J Knee Surg. 2007;20(2):134-41.

Jackson JP, Waugh W. Tibial osteotomy for osteoarthritis of the knee. J Bone Joint Surg Br. 1961;43(4):746-51.

Jackson JP. Osteotomy for osteoarthritis of the knee. J Bone Joint Surg Br. 1958;40(4):826.

Kassim RA, Saleh KJ, Yoon P, Haas S. Varus distal femoral osteotomy. Techn Knee Surg. 2002;1:54-9.

Kendoff D, Citak M, Pearle A, Gardner MJ, Hankemeier S, Krettek C, Hüfner T. Influence of lower limb rotation in navigation alignment analysis: implications for high tibial osteotomies. Knee Surg Sports Traumatol Arthrosc. 2007;15(8):1003-8.

Kendoff DO, Fragomen AT, Pearle AD, Citak M, Rozbruch SR. Computer navigation and fixator-assisted femoral osteotomy for correction of malunion after periprosthetic femur fracture. J Arthroplasty. 2010;25(2):333.e13-9.

Kettelkamp DB, Chao EY. A method for quantitative analysis of medial and lateral compression forces at the knee during standing. Clin Orthop Relat Res. 1972;83:202-13. 
Kettelkamp DB. Proximal tibial osteotomy. Clin Orthop Relat Res. 1974;(103):46.

Kosashvili Y, Safir O, Gross A, Morag G, Lakstein D, Backstein D. Distal femoral varus osteotomy for lateral osteoarthritis of the knee: a minimum tenyear follow-up. Int Orthop. 2010;34(2):249-54.

Krettek C, Könemann B, Farouk O, Miclau T, Kromm A, Tscherne $H$. Experimental study of distal interlocking of a solid tibial nail: radiationindependent distal aiming device (DAD) versus freehand technique (FHT). $J$ Orthop Trauma. 1998;12(6):373-8.

Lorenz S, Morgenstern M, Imhoff AB. Development of an image-free navigation toll for high tibial osteotomy. Oper Tech Orthop. 2007;17(1) 58-65.

Maquet P. Valgus osteotomy for osteoarthritis of the knee. Clin Orthop Relat Res. 1976;(120):143-8.

Mason JB, Fehring TK, Estok R, Banel D, Fahrbach K. Meta-analysis of alignment outcomes in computer-assisted total knee arthroplasty surgery. $J$ Arthroplasty. 2007;22(8):1097-106. 
Matthews LS, Goldstein SA, Malvitz TA, Katz BP, Kaufer H. Proximal tibial osteotomy. Factors that influence the duration of satisfactory function. Clin Orthop Relat Res. 1988;(229):193-200.

Maurer F, Wassmer G. High tibial osteotomy: does navigation improve results? Orthopedics. 2006;29(10 Suppl):S130-2.

McDermott AG, Finklestein JA, Farine I, Boynton EL, Maclntosh DL, Gross A. Distal femoral varus osteotomy for valgus deformity of the knee. J Bone Joint Surg Am. 1988;70(1):110-6.

Morales LAM, Gomez Navalon LA, Zorrilla Ribot P, Salido Valle JA. Treatment of osteoarthritis of the knee with valgus deformity by means of varus osteotomy. Acta Orthop Belg. 2000;66(3):272-8.

Nagel A, Insall JN, Scuderi GR. Proximal tibial osteotomy. A subjective outcome study. J Bone Joint Surg Am. 1996;78(9):1353-8.

Pearle AD, Goleski P, Musahl V, Kendoff D. Reliability of image-free navigation to monitor lower-limb alignment. $J$ Bone Joint Surg Am. 2009;91(Suppl 1):90-4. 
Puddu G, Cipolla M, Cerullo G, Franco V, Giannì E. Osteotomies: the surgical treatment of the valgus knee. Sports Med Arthrosc. 2007;15(1):1522.

Puddu G, Cipolla M, Cerullo G, Franco V, Giannì E. Which osteotomy for a valgus knee? Int Orthop. 2010;34(2):239-47.

Puddu G, Franco V. Femoral antivalgus opening wedge osteotomy. Oper. Tech Sports Med. 2000; 8: 56-60.

Reising K, Strohm PC, Hauschild O, Schmal H, Khattab M, Südkamp NP, Niemeyer P. Computer-assisted navigation for the intraoperative assessment of lower limb alignment in high tibial osteotomy can avoid outliers compared with the conventional technique. Knee Surg Sports Traumatol Arthrosc. 2013;21(1):181-8.

Rosenberger RE, Hoser C, Quirbach S, Attal R, Hennerbichler A, Fink C. Improved accuracy of component alignment with the implementation of image-free navigation in total knee arthroplasty. Knee Surg Sports Traumatol Arthrosc. 2008;16(3):249-57.

Rudan JF, Simurda MA. High tibial osteotomy. A prospective clinical and roentgenographic review. Clin Orthop Relat Res. 1990;(255):251-6. 
Salzmann GM, Ahrens P, Naal FD, El-Azab H, Spang JT, Imhoff AB, Lorenz S. Sporting activity after high tibial osteotomy for the treatment of medial compartment knee osteoarthritis. Am J Sports Med. 2009;37(2):312-8.

Saragaglia D, Blaysat M, Mercier N, Grimaldi M. Results of forty two computer-assisted double level osteotomies for severe genu varum deformity. Int Orthop. 2012;36(5):999-1003.

Saragaglia D, Mercier N, Colle PE. Computer-assisted osteotomies for genu varum deformity: which osteotomy for which varus? Int Orthop. 2010;34(2):185-90.

Saragaglia D, Roberts J. Navigated osteotomies around the knee in 170 patients with osteoarthritis secondary to genu varum. Orthopedics. 2005;28(10 Suppl):s1269-74.

Sastre S, Torner P, Maculé F. Knee osteotomy: navigation guided and arthroscopy assisted. Knee Surg Sports Traumatol Arthrosc. 2007;15(10):1215-8.

Scott D, Smith C, Lohmander S, Chard . Clinical Evidence. Londres: BMJ Publishing Group, 2004. p.1560-88: Osteoarthritis. 
Silva ALP, Demange MK, Gobbi RG, Silva TFC, Pecora JR, Croci AT. Tradução e validação da escala Knee Society Score - KSS para a língua portuguesa. Acta Ortop Bras. 2012;20(1):25-30.

Siston RA, Giori NJ, Goodman SB, Delp SL. Surgical navigation for total knee arthroplasty: a perspective. J Biomech. 2007;40(4):728-35.

Song EK, Seon JK, Park SJ, Seo HY. Navigated open wedge high tibial osteotomy. Sports Med Arthrosc. 2008;16(2):84-90.

Sparmann M, Wolke B, Czupalla H, Banzer D, Zink A. Positioning of total knee arthroplasty with and without navigation support. A prospective, randomised study. J Bone Joint Surg Br. 2003;85(6):830-5.

Stahelin T, Hardegger F, Ward JC. Supracondylar osteotomy of the femur with use of compression. Osteosynthesis with a malleable implant. $J$ Bone Joint Surg Am. 2000;82(5):712-22.

Stulberg SD, Picard F, Saragaglia D. Computer-assisted total knee replacement arthroplasty. Oper Tech Orthop. 2000; 10(1) 25-35.

Symmons D, Mathers C, Pleger B. Global burden of osteoarthritis in the year 2000. Geneva: WHO, 2002. p.1-26. 
Taylor RH, Joskowicz L, Williamson B, Guéziec A, Kalvin A, Kazanzides P, Van Vorhis R, Yao J, Kumar R, Bzostek A, Sahay A, Börner M, Lahmer A. Computer-integrated revision total hip replacement surgery: concept and preliminary results. Med Image Anal. 1999;3(3):301-19.

Taylor RH, Lavallee S, Burdea GC, Mosges R. Cambridge, MA: MIT Press, 1995. p. xiii-xviii: Introduction.

Taylor RH, Lavellee S, Burdea GC, Mösges R. Computer-integrated surgery. Technology and clinical applications. 1996. Clin Orthop Relat Res. 1998;(354):5-7.

Torner P, Sastre S, Maculé F, Núnez M, Segur JM, Lozano LI. Complex osteotomy assisted with navigation and arthroscopy around knee. Eur $J$ Orthop Surg Traumatol. 2008;18(7):515-9.

Verheyen CC. Preplanning for correctional osteotomies: sculpture your result. Arch Orthop Trauma Surg. 2006;126(8):522-5.

Wang JW, Hsu CC. Distal femoral varus osteotomy for osteoarthritis of the knee. Surgical technique. J Bone Joint Surg Am. 2006;88(Suppl 1 Pt 1):1008. 
Wright J, Heck D, Hawker G, Dittus R, Freund D, Joyce D, Paul J, Young W, Coyte P. Rates of tibial osteotomies in Canada and the United States. Clin Orthop Relat Res. 1995;(319):266-75.

Zarrouk A, Bouzidi R, Karray B, Kammoun S, Mourali S, Kooli M. Distal femoral varus osteotomy outcome: is associated femoropatella osteoarthritis consequential? Orthop Traumatol Surg Res. 2010;96(6):632-6.

Zilber S, La rrouy M, Sedel L, Nizard R. Distal femoral varus osteotomy for symptomatic genu valgum: long-term results and review of the literature. Rev Chir Orthop Reparatrice Appar Mot. 2004;90(7):659-65. 